NASA/TM-1999-208491

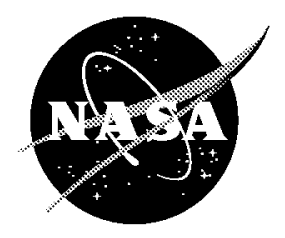

\title{
Rare Earth Doped High Temperature Ceramic Selective Emitters
}

Donald L. Chubb

Lewis Research Center, Cleveland, Ohio

AnnaMarie Pal, Martin O. Patton, and Phillip P. Jenkins

Essential Research, Inc., Cleveland, Ohio 
Since its founding, NASA has been dedicated to the advancement of aeronautics and space science. The NASA Scientific and Technical Information (STI) Program Office plays a key part in helping NASA maintain this important role.

The NASA STI Program Office is operated by Langley Research Center, the Lead Center for NASA's scientific and technical information. The NASA STI Program Office provides access to the NASA STI Database, the largest collection of aeronautical and space science STI in the world. The Program Office is also NASA's institutional mechanism for disseminating the results of its research and development activities. These results are published by NASA in the NASA STI Report Series, which includes the following report types:

- TECHNICAL PUBLICATION. Reports of completed research or a major significant phase of research that present the results of NASA programs and include extensive data or theoretical analysis. Includes compilations of significant scientific and technical data and information deemed to be of continuing reference value. NASA's counterpart of peerreviewed formal professional papers but has less stringent limitations on manuscript length and extent of graphic presentations.

- TECHNICAL MEMORANDUM. Scientific and technical findings that are preliminary or of specialized interest, e.g., quick release reports, working papers, and bibliographies that contain minimal annotation. Does not contain extensive analysis.

- CONTRACTOR REPORT. Scientific and technical findings by NASA-sponsored contractors and grantees.
- CONFERENCE PUBLICATION. Collected papers from scientific and technical conferences, symposia, seminars, or other meetings sponsored or cosponsored by NASA.

- SPECIAL PUBLICATION. Scientific, technical, or historical information from NASA programs, projects, and missions, often concerned with subjects having substantial public interest.

- TECHNICAL TRANSLATION. Englishlanguage translations of foreign scientific and technical material pertinent to NASA's mission.

Specialized services that complement the STI Program Office's diverse offerings include creating custom thesauri, building customized data bases, organizing and publishing research results ... even providing videos.

For more information about the NASA STI Program Office, see the following:

- Access the NASA STI Program Home Page at http://www.sti.nasa.gov

- E-mail your question via the Internet to help@sti.nasa.gov

- Fax your question to the NASA Access Help Desk at (301) 621-0134

- Telephone the NASA Access Help Desk at (301) 621-0390

- Write to:

NASA Access Help Desk

NASA Center for AeroSpace Information 7121 Standard Drive

Hanover, MD 21076 
NASA/TM-1999-208491

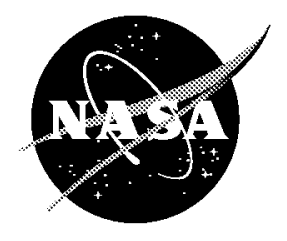

\section{Rare Earth Doped High Temperature Ceramic Selective Emitters}

Donald L. Chubb

Lewis Research Center, Cleveland, Ohio

AnnaMarie Pal, Martin O. Patton, and Phillip P. Jenkins

Essential Research, Inc., Cleveland, Ohio

National Aeronautics and

Space Administration

Lewis Research Center 
Available from

NASA Center for Aerospace Information 7121 Standard Drive

Hanover, MD 21076

Price Code: A03
National Technical Information Service 5285 Port Royal Road Springfield, VA 22100 Price Code: A03 


\title{
RARE EARTH DOPED HIGH TEMPERATURE CERAMIC SELECTIVE EMITTERS
}

\author{
Donald L. Chubb \\ National Aeronautics and Space Administration \\ Lewis Research Center \\ Cleveland, Ohio 44135 \\ AnnaMaria T. Pal, Martin O. Patton, and Phillip P. Jenkins \\ Essential Research, Inc. \\ Cleveland, Ohio 44122
}

Abstract

As a result of their electron structure, rare earth ions in crystals at high temperature emit radiation in several narrow bands rather than in a continuous blackbody manner. This study develops a spectral emittance model for films of rare earth containing materials. Although there are several possible rare earth doped high temperature materials, this study was confined to rare earth aluminum garnets. Good agreement between experimental and theoretical spectral emittances was found for erbium, thulium and erbium-holmium aluminum garnets. Spectral emittances of these films are sensitive to temperature differences across the film. Emitter efficiency is also a sensitive function of temperature. For thulium aluminum garnet the efficiency is 0.38 at $1700 \mathrm{~K}$ but only 0.19 at $1262 \mathrm{~K}$.

\section{Introduction}

A selective emitter is a material that emits optical radiation in a few emission bands rather than in a continuous spectrum like a blackbody or a gray body (constant emittance). Thermophotovoltaic (TPV) energy conversion is the main application for selective emitters. In TPV energy conversion, the selective emitter converts thermal energy to near infrared radiation at wavelengths where photovoltaic energy conversion is efficient. A TPV system is rather simple, consisting of three main components, a heat source, an emitter and a photovoltaic cell array.

The ideal selective emitter would have a single emission band with an emittance approaching one within the band and negligible emittance outside the emission band. For the photon energy or wavelength region of interest for TPV energy conversion $(1000$ to $3000 \mathrm{~nm})$, an electronic transition of an atom or molecule is required to produce the desired radiation. However, when atoms are compressed to solid state densities the emission is not characterized by narrow band emission as with an isolated atom, but by a continuous emission spectrum.

Fortunately, there is a group of atoms that even at solid state densities behave nearly like isolated atoms. These are the lanthanides or rare earth atoms. For doubly and triply charged ions of these elements in crystals the orbits of the valence $4 f$ electrons, which account for emission and absorption, lie inside the $5 s$ and $5 p$ electron orbits. The $5 s$ and $5 p$ electrons "shield" the $4 f$ valence electrons from the surrounding 
ions in the crystal. As a result, the rare earth ions in the solid state emit in narrow bands rather than in a continuous gray body manner. For the temperatures of interest ( $1200 \leq T \leq 2000 \mathrm{~K})$ the rare earths of most interest have a strong emission band in the near infrared $(800 \leq \lambda \leq 3000 \mathrm{~nm})$ resulting from electron transitions from the first excited state manifold to the ground state manifold. Because of the location of their emission bands, the rare earths of most interest for selective emitters are ytterbium $(\mathrm{Yb})$, thulium (Tm), erbium (Er), holmium (Ho) and dysprosium (Dy). The spectra of the rare earth ions in crystals have been extensively studied. Most of this work is summarized in the text of Dieke. ${ }^{1}$

The first selective emitters investigated ${ }^{2}$ were made by sintering rare earth oxide powders. These emitters showed the strong emission bands. However, emittance outside the emission bands was also large so that the emitter efficiency was low. In the late 1980's Nelson and Parent ${ }^{3,4}$ reported a large improvement in rare earth oxide emitters. Their emitters are constructed of bundles of small diameter (5 to $10 \mu \mathrm{m}$ ) fibers similar to the construction of the Welsbach mantle used in gas lanterns. The very small characteristic dimension of these emitters results in low emittance outside the emission band and thus greatly increased efficiency. The fibrous selective emitters are well suited to a combustion driven TPV system where the fibrous mantle surrounds the flame. However, for coupling to other thermal energy sources likely to be used for a space TPV system, such as nuclear or solar, the fibrous emitter is not so well suited. For a space application a planar geometry is more applicable for coupling to a nuclear or solar thermal energy source. As just stated, it was the small characteristic dimension that made the fibrous emitters efficient. Another geometry for achieving a small characteristic dimension and also easily coupling to any thermal source is a film. A film containing a rare earth on a low emittance substrate, which blocks radiation from the thermal source, can be easily attached to any thermal source. In addition, a film is more durable than a fibrous geometry. Therefore, we began a theoretical and experimental investigation of rare earth containing film selective emitters. ${ }^{5-13}$

Our first attempt at producing a film selective emitter was by electron beam evaporation of pure rare earth oxides. However, we soon learned that film thicknesses on the order 1 to $10 \mu \mathrm{m}$ were not sufficient to produce large emittance. Film thicknesses of 0.1 to $1 \mathrm{~mm}(100$ to $1000 \mu \mathrm{m})$ are required. Evaporation is not applicable for films of that thickness so we looked for other methods. We knew that yttrium aluminum garnet (YAG) could be doped with rare earths and grown in single crystal form. Therefore, with material in this form we could cut and polish a sample to any thickness. Thus our first successful selective emitters were single crystal rare earth doped YAG. There are many other possible high temperature host materials for rare earths. Some of these possible hosts are shown in Table I.

The optical properties that characterize a selective emitter are the extinction coefficient, $\alpha_{\lambda}$, which is the sum of the absorption coefficient, $a_{\lambda}$, and the scattering coefficient, $\sigma_{\lambda}$, and the index of refraction, $n$. Knowing $\alpha_{\lambda}$ and $n$, the spectral emittance, $\varepsilon_{\lambda}$, can be calculated. In the next section the model for making this calculation will be developed. Figure 1 shows the extinction coefficient for single crystal erbium aluminum garnet $\left(\mathrm{Er}_{3} \mathrm{Al}_{5} \mathrm{O}_{12}\right)$. The method for obtaining $\alpha_{\lambda}$ will be described in the Experimental Measurements section. Although the results in Fig. 1 apply for erbium aluminum garnet, qualitatively similar results will occur for any of the possible erbium containing materials. 
The major emission band for Er occurs at wavelength, $\lambda \approx 1500 \mathrm{~nm}$, with smaller bands occurring at $\lambda \approx 970 \mathrm{~nm}, 800 \mathrm{~nm}$ and $640 \mathrm{~nm}$. Most all high temperature ceramic materials have large extinction coefficient and thus large absorptance and emittance at long wavelengths. For YAG and the rare earth aluminum garnets this region begins at $\lambda \approx 5000 \mathrm{~nm}$. Obviously this long wavelength region of high emittance is undesirable for a selective emitter. An efficient selective emitter is one that emits most of its energy in the large emission band.

In the next section the theoretical model for calculating the spectral emittance, $\varepsilon_{\lambda}$, of a one dimensional film will be presented. Following that the experimental method for obtaining $\alpha_{\lambda}, n$ and $\varepsilon_{\lambda}$ is described. Finally, experimental and theoretical results for $\varepsilon_{\lambda}$ and emitter efficiency will be presented.

\section{Spectral Emittance Model}

Figure 2 is a schematic diagram of the film emittance model. Thermal energy, $Q_{i n}$, enters through the metal substrate. Part of the thermal input leaves the film at $x=d$ as radiation flux $Q(d)$. The remaining part leaves by thermal conduction, $-\left.k_{t h} \frac{d T}{d x}\right|_{x=d}$. As a result, the energy equation is the following.

$$
-k_{\text {th }} \frac{d T}{d x}+Q(x)=Q_{\text {in }}
$$

Where $k_{\text {th }}$ is the thermal conductivity (assumed to be constant) and T is the film temperature. The radiation flux is defined as follows.

$$
Q(x)=\int_{0}^{\infty} q_{\lambda}(x, \lambda) d \lambda \quad w / \mathrm{cm}^{2}
$$

Where $q$ is the radiation flux at wavelength, $\lambda$, and has the units $w / \mathrm{cm}^{2} \mathrm{~nm}$. The radiation flux will always be less than the blackbody flux, $\sigma_{\mathrm{sb}}{ }^{\top}{ }_{\mathrm{s}}^{4}$, therefore defining the following dimensionless variables

$$
\overline{\mathrm{T}}=\frac{\mathrm{T}}{\mathrm{T}_{\mathrm{S}}}, \quad \overline{\mathrm{Q}}=\frac{\mathrm{Q}}{\sigma_{\mathrm{sb}} \mathrm{T}_{\mathrm{s}}^{4}}, \quad \overline{\mathrm{x}}=\frac{\mathrm{x}}{\mathrm{d}}
$$

results in the following energy equation.

$$
-\frac{d \bar{T}}{d \bar{x}}+\gamma \bar{Q}=\gamma \bar{Q}_{\text {in }}=\text { constant }
$$


Where $\sigma_{\mathrm{sb}}$ is the Stefan Boltzmann constant $\left(5.67 \times 10^{-12} \mathrm{~W} / \mathrm{cm}^{2}{ }^{\circ} \mathrm{K}\right)$ and

$$
\gamma \equiv \frac{\sigma_{\mathrm{sb}} T_{\mathrm{s}}^{3} \mathrm{~d}}{\mathrm{k}_{\mathrm{th}}}
$$

Thus, if $\gamma<<1$ the radiation term can be neglected and the solution to Eq. (4) is the following.

$$
\overline{\mathrm{T}}=1-\overline{\mathrm{x}} \Delta \mathrm{T}
$$

Where,

$$
\Delta T=\frac{T_{s}-T_{f}}{T_{S}}
$$

For most of the materials considered for rare earth selective emitters $\mathrm{k}_{\text {th }} \geq 0.01 \mathrm{w} / \mathrm{cmK}, \mathrm{T}_{\mathrm{s}} \leq 2000 \mathrm{~K}$ and $\mathrm{d} \leq 0.05 \mathrm{~cm}$. Thus, $\gamma$ will be less than 0.2. The linear temperature gradient given by equation (6) will be used in the following emittance calculation. In a recent study ${ }^{14}$ the complete energy equation (eq. (4)) was solved. Based on those results, the linear temperature variation (eq. (6)) is a good approximation.

To determine the spectral emittance, $\varepsilon_{\lambda}$, the radiation flux leaving the film at $x=d$, $q_{\lambda}(d)$, must be calculated since $\varepsilon_{\lambda}$ is defined as follows.

$$
\varepsilon_{\lambda} \equiv \frac{q_{\lambda}(d)}{e_{b s}\left(\lambda, T_{s}\right)}=\frac{q_{\lambda}(d)}{\pi i_{b s}\left(\lambda, T_{s}\right)}
$$

Where $e_{b s}\left(\lambda, T_{s}\right)$ is the blackbody emissive power and $T_{s}$ is the substrate temperature.

$$
\mathrm{e}_{\mathrm{bs}}\left(\lambda, \mathrm{T}_{\mathrm{s}}\right)=\pi \mathrm{i}_{\mathrm{bs}}\left(\lambda, \mathrm{T}_{\mathrm{s}}\right)=\frac{2 \pi \mathrm{hc_{ \textrm {o } } ^ { 2 }}}{\lambda^{5}\left[\exp \left(\mathrm{hc_{ \textrm {o } }} / \lambda \mathrm{k} \mathrm{T}_{\mathrm{s}}\right)-1\right]}
$$

Here $i_{b s}\left(\lambda, T_{s}\right)$ is the blackbody intensity ( $w / \mathrm{cm}^{2} \mathrm{~nm}$ steradian), $\mathrm{h}$ is Plank's constant, $\mathrm{k}$ is Boltzmann's constant, and $\mathrm{c}_{0}$ is the vacuum speed of light. Notice that $\varepsilon_{\lambda}$ has been defined in terms of the substrate temperature, $T_{s}$. The spectral emittance could be defined in terms of the film surface temperature, $T_{f}$, or some combination of $T_{f}$ and $T_{s}$. However, defining $\varepsilon_{\lambda}$ in terms of $T_{s}$ means $\varepsilon_{\lambda} \leq 1$ in all cases since $e_{b s}\left(\lambda, T_{s}\right) \geq q_{\lambda}(d)$. This definition agrees with the usual concept of emittance.

The following analysis is similar to that given in reference 13 . To calculate $q_{\lambda}$ we require the radiative transfer equations for radiation intensity moving in the $+x$ direction at $x=d, i_{\lambda}^{+}(d, \cos \theta)$, and the intensity in the $-x$ direction at $x=0, i_{\lambda}^{-}(0, \cos \theta) .{ }^{15}$ 


$$
\begin{gathered}
i_{\lambda}^{+}\left(K_{d}, \mu\right)=i_{\lambda}^{+}(0, \mu) \exp \left(-\frac{K_{d}}{\mu}\right)+\int_{0}^{K_{d}} S_{\lambda}\left(K^{*}, \mu\right) \exp \left(-\frac{K_{d}-K^{*}}{\mu}\right) \frac{d K^{*}}{\mu} \quad 0 \leq \mu=\cos \theta \leq 1 \\
i_{\lambda}^{-}(0, \mu)=i_{\lambda}^{-}\left(K_{d}, \mu\right) \exp \left(-\frac{K_{d}}{\mu}\right)-\int_{0}^{K_{d}} S_{\lambda}\left(K^{*}, \mu\right) \exp \left(\frac{K^{*}}{\mu}\right) \frac{d K^{*}}{\mu} \quad-1 \leq \mu=\cos \theta \leq 0
\end{gathered}
$$

Equations (10) and (11) have been written in terms of the optical depth, $K$, rather than the coordinate $\mathrm{x}$.

$$
\begin{aligned}
& K=\alpha_{\lambda} x \\
& K_{d}=\alpha_{\lambda} d
\end{aligned}
$$

Where $\alpha_{\lambda}$ is the extinction coefficient, assumed independent of $x$, and is the sum of the absorption coefficient, $a_{\lambda}$, and the scattering coefficient, $\sigma_{\lambda}$.

$$
\alpha_{\lambda}=a_{\lambda}+\sigma_{\lambda}
$$

Appearing in Eqs. (10) and (11) is the so-called source function, $S_{\lambda}(K, \mu),{ }^{15}$ which in the case of isotropic scattering $S_{\lambda}$ is independent of $\mu\left(S_{\lambda}(K, \mu)=S_{\lambda}(K)\right)$.

The intensities $\mathrm{i}_{\lambda}^{-}\left(\mathrm{K}_{\mathrm{d}}\right)$ and $\mathrm{i}_{\lambda}^{+}(0)$ are obtained from the following boundary conditions at $\mathrm{K}=0$ and $\mathrm{K}=\mathrm{K}_{\mathrm{d}}$, assuming the boundaries are diffuse (intensities independent of $\theta$ ).

$$
\begin{gathered}
\mathrm{i}_{\lambda}^{-}\left(\mathrm{K}_{\mathrm{d}}\right)=\rho_{\mathrm{f}} \mathrm{i}_{\lambda}^{+}\left(\mathrm{K}_{\mathrm{d}}\right) \quad \text { at } \mathrm{K}=\mathrm{K}_{\mathrm{d}} \\
\mathrm{i}_{\lambda}^{+}(0)=\rho_{\mathrm{fs}} \mathrm{i}_{\bar{\lambda}}^{-}(0)+\varepsilon_{\mathrm{fs}} \mathrm{i}_{\lambda \mathrm{b}}\left(\lambda, \mathrm{T}_{\mathrm{s}}\right) \quad \text { at } \mathrm{K}=0
\end{gathered}
$$

Where $\rho_{\mathrm{fo}}$ is the reflectance at the vacuum-film interface, $\rho_{\mathrm{fs}}$ is the reflectance at the film-substrate interface and $\varepsilon_{\mathrm{fs}}$ is the emittance of the substrate into the film. Equation (14a) states that the intensity moving in the $-x$ direction at $x=d$ is equal to the reflected intensity. At $x=0$ Eq. (14b) states that $i_{\lambda}^{+}(0)$ is the sum of the reflected intensity and radiation emitted from the substrate into the film.

At the film-vacuum interface total reflection occurs for certain angles of incidence, $\theta$. At an interface between a material with an index of refraction, $n_{i}$, and a material with index of refraction $n_{j}$, where $n_{i}>n_{j}$, radiation moving from $i$ into $j$ with an angle of incidence $\theta>\theta_{M}$, where $\theta_{M}$ is given by Snell's Law will be totally reflected. Since $n_{f}>n_{0}$, for the film-vacuum interface we have the following result for the reflectance, $\rho_{\mathrm{fO}}$. 


$$
\rho_{\mathrm{f} 0}=1 \quad \text { for } \quad \theta \geq \theta_{M} \quad \text { where } \quad \cos ^{2} \theta_{M}=\mu_{M}^{2}=1-\left(\frac{n_{o}}{n_{f}}\right)^{2}
$$

For the case where $\theta<\theta_{M}\left(\mu>\mu_{M}\right)$ we approximate $\rho_{f 0}$ by the reflectance for normal incidence. ${ }^{15}$

$$
\rho_{\mathrm{fo}}=\left(\frac{\mathrm{n}_{\mathrm{f}}-\mathrm{n}_{\mathrm{o}}}{\mathrm{n}_{\mathrm{f}}+\mathrm{n}_{\mathrm{o}}}\right)^{2} \quad \theta<\theta_{\mathrm{M}}\left(\mu>\mu_{M}\right)
$$

Since the substrate will be a metal, $n_{s}>n_{f}$, total reflection will not occur at the film-substrate interface. In this case we approximate $\rho_{\mathrm{fs}}$ by the normal reflectance for a metal into a dielectric. ${ }^{15}$

$$
\rho_{\mathrm{fs}}=\frac{\left(\mathrm{n}_{\mathrm{s}}-\mathrm{n}_{\mathrm{f}}\right)^{2}+\mathrm{n}_{\mathrm{sl}}^{2}}{\left(\mathrm{n}_{\mathrm{s}}+\mathrm{n}_{\mathrm{f}}\right)^{2}+\mathrm{n}_{\mathrm{sl}}^{2}}
$$

Where $n_{s}$ is the real part and $n_{s \mid}$ is the imaginary part of the substrate index of refraction. Since the substrate is opaque.

$$
\varepsilon_{\mathrm{fs}}=1-\rho_{\mathrm{fs}}
$$

Now we are prepared to calculate $q_{\lambda}\left(K_{d}\right)$. From Eqs. (10), (11), (14a) and (14b) we obtain 4 simultaneous equations for the 4 fluxes $q_{\lambda}^{+}(0), q_{\lambda}^{-}(0), q_{\lambda}^{+}\left(K_{d}\right), q_{\lambda}^{-}\left(K_{d}\right)$. Once those equations are solved then $q_{\lambda}\left(K_{d}\right)$ can be determined.

$$
q_{\lambda}\left(K_{d}\right)=q_{\lambda}^{+}\left(K_{d}\right)-q_{\lambda}^{-}\left(K_{d}\right)
$$

After a great deal of algebra, which is outlined below, the result for $q_{\lambda}\left(K_{d}\right)$ and thus $\varepsilon_{\lambda}$ is obtained.

At $x=0$ the flux moving in the $-x$ direction is the following.

$$
q_{\lambda}^{-}(0)=-2 \pi \int_{\theta=\pi / 2}^{\pi} i_{\lambda}^{-}(0, \cos \theta) \cos \theta \sin \theta d \theta=2 \pi \int_{0}^{-1} i_{\lambda}^{-}(0, \mu) \mu d \mu
$$

Using Eq. (11) yields the following.

$$
\mathrm{q}_{\lambda}^{-}(0)=2 \mathrm{q}_{\lambda}^{-}\left(\mathrm{K}_{\mathrm{d}}\right) \mathrm{E}_{3}\left(\mathrm{~K}_{\mathrm{d}}\right)+\Phi_{-}\left(\mathrm{K}_{\mathrm{d}}\right)
$$

Since the boundaries are assumed diffuse, $q_{\lambda}^{-}\left(K_{d}\right)=\pi i_{\lambda}^{-}\left(K_{d}\right)$. At $x=d$ the flux moving in the $+x$ direction is the following. 


$$
\mathrm{q}_{\lambda}^{+}\left(\mathrm{K}_{\mathrm{d}}\right)=2 \pi \int_{\theta=0}^{\pi / 2} \mathrm{i}_{\lambda}^{+}\left(\mathrm{K}_{\mathrm{d}}, \cos \theta\right) \cos \theta \sin \theta \mathrm{d} \theta=2 \pi \int_{0}^{1} \mathrm{i}_{\lambda}^{+}\left(\mathrm{K}_{\mathrm{d}}, \mu\right) \mu \mathrm{d} \mu
$$

Using Eq. (10) yields the following

$$
\mathrm{q}_{\lambda}^{+}\left(\mathrm{K}_{\mathrm{d}}\right)=2 \mathrm{q}_{\lambda}^{+}(0) \mathrm{E}_{3}\left(\mathrm{~K}_{\mathrm{d}}\right)+\Phi_{+}\left(\mathrm{K}_{\mathrm{d}}\right)
$$

Where the diffuse boundary condition means that $\mathrm{q}_{\lambda}^{+}(0)=\pi \mathrm{i}_{\lambda}^{+}(0)$.

At $x=0$ the flux moving in the $+x$ direction is the following.

$$
\mathrm{q}_{\lambda}^{+}(0)=-2 \pi \int_{\theta=\pi / 2}^{\pi} \rho_{\mathrm{fs}} \mathrm{i}_{\lambda}^{-}(0, \cos \theta) \cos \theta \sin \theta d \theta+2 \pi \int_{\theta=0}^{\pi / 2} \varepsilon_{\mathrm{fs}} \mathrm{i}_{\mathrm{bs}}\left(\lambda, \mathrm{T}_{\mathrm{s}}\right) \cos \theta \sin \theta \mathrm{d} \theta
$$

Using Eq. (11) for $\mathrm{i}_{\lambda}^{-}(0, \cos \theta)$ yields the following.

$$
\mathrm{q}_{\lambda}^{+}(0)=\rho_{\mathrm{fs}}\left[2 \mathrm{q}_{\bar{\lambda}}\left(\mathrm{K}_{\mathrm{d}}\right) \mathrm{E}_{3}\left(\mathrm{~K}_{\mathrm{d}}\right)+\Phi_{-}\left(\mathrm{K}_{\mathrm{d}}\right)\right]+\varepsilon_{\mathrm{fs}} \mathrm{e}_{\mathrm{bs}}\left(\lambda, \mathrm{T}_{\mathrm{s}}\right)
$$

The flux at $x=d$ moving in the $-x$ direction is the following.

$$
\begin{aligned}
\mathrm{q}_{\lambda}^{-}\left(\mathrm{K}_{\mathrm{d}}\right)=2 \pi \int_{\theta=0}^{\pi / 2} \rho_{\mathrm{fo}} \mathrm{i}_{\lambda}^{+}\left(\mathrm{K}_{\mathrm{d}}, \cos \theta\right) \cos \theta \sin \theta \mathrm{d} \theta & =2 \pi\left[\int_{0}^{\theta} \mathrm{i}_{\lambda}^{+}\left(\mathrm{K}_{\mathrm{d}}, \cos \theta\right) \cos \theta \sin \theta \mathrm{d} \theta\right. \\
& \left.+\rho_{\mathrm{f} 0} \int_{\theta_{\mathrm{M}}}^{\pi / 2} \mathrm{i}_{\lambda}^{+}\left(\mathrm{K}_{\mathrm{d}}, \cos \theta\right) \cos \theta \sin \theta \mathrm{d} \theta\right]
\end{aligned}
$$

Using Eq. (10) for $i_{\lambda}^{+}\left(K_{d}, \cos \theta\right)$ yields the following

$$
q_{\lambda}^{-}\left(K_{d}\right)=2 q_{\lambda}^{+}(0)\left[\rho_{f 0} E_{3}\left(K_{d}\right)+\left(1-\rho_{f 0}\right) \mu_{m}^{2} E_{3}\left(\frac{K_{d}}{\mu_{M}}\right)\right]+\rho_{f 0} \Phi_{+}\left(K_{d}\right)+\left(1-\rho_{f 0}\right) \Phi_{M}\left(\frac{K_{d}}{\mu_{M}}\right)
$$

Equations (19b), (20b), (21b) and (22b) make up the 4 equations for the fluxes $q_{\lambda}^{-}(0)$, $\mathrm{q}_{\lambda}^{+}\left(\mathrm{K}_{\mathrm{d}}\right), \mathrm{q}_{\lambda}^{+}(0)$ and $\mathrm{q}_{\lambda}^{-}\left(\mathrm{K}_{\mathrm{d}}\right)$. Appearing in those equations are the following quantities,

$$
\begin{gathered}
\Phi_{+}\left(K_{d}\right)=2 \pi \int_{0}^{K_{d}} S(K) E_{2}\left(K_{d}-K\right) d K \\
\Phi_{-}\left(K_{d}\right)=2 \pi \int_{0}^{K_{d}} S(K) E_{2}(K) d K \\
\Phi_{M}\left(\frac{K_{d}}{\mu_{M}}\right)=2 \pi \mu_{M} \int_{0}^{K_{d}} S(K) E_{2}\left(\frac{K_{d}-K}{\mu_{M}}\right) d K
\end{gathered}
$$


and the exponential integral $E_{n}(x)$ defined as follows.

$$
E_{n}(x)=\int_{0}^{1} z^{n-2} \exp \left(-\frac{x}{z}\right) d z
$$

Solving the 4 simultaneous equations yields the following result.

$$
\begin{aligned}
& q_{\lambda}\left(K_{d}\right)=q_{\lambda}^{+}\left(K_{d}\right)-q_{\lambda}^{-}\left(K_{d}\right)=\frac{\left(1-\rho_{f 0}\right)}{D E N} \\
&\left\{2\left[\varepsilon_{f s} e_{b s}\left(\lambda, T_{s}\right)+\rho_{f s} \Phi_{-}\left(K_{d}\right)\right] h_{-}+\Phi_{+}\left(K_{d}\right) h_{+}-\Phi_{M}\left(\frac{K_{d}}{\mu_{M}}\right) h_{M}\right\}
\end{aligned}
$$

Where

$$
\begin{gathered}
h_{-}=E_{3}\left(K_{d}\right)-\mu_{M}^{2} E_{3}\left(\frac{K_{d}}{\mu_{M}}\right) \\
h_{+}=1-4 \rho_{f s} \mu_{M}^{2} E_{3}\left(K_{d}\right) E_{3}\left(\frac{K_{d}}{\mu_{M}}\right) \\
h_{M}=1-4 \rho_{f s} E_{2}^{2}\left(K_{d}\right) \\
D E N=1-4 \rho_{f s} E_{3}\left(K_{d}\right)\left[\rho_{f 0} E_{3}\left(K_{d}\right)+\left(1-\rho_{f 0}\right) \mu_{M}^{2} E_{3}\left(\frac{K_{d}}{\mu_{M}}\right)\right]
\end{gathered}
$$

The result for $q_{\lambda}\left(K_{d}\right)$ given by Eq. (27) is slightly different than the result in Ref. 13 (Eq. (20)). In Ref. 13 a different substrate emittance model was used and the boundary condition at $x=d$ was applied incorrectly in calculating $q_{\lambda}^{-}\left(K_{d}\right)$. As a result, DEN given by Eq. (31) replaces $D$ in the denominator and $h_{M}$ replaces $D$ as the coefficient of $\Phi_{M}$ in Eq. (20) of Ref. 13. Also, in Eq. (20) of Ref. $13 \varepsilon_{\mathrm{fs}}$ replaces $\left(n_{\lambda f} / n_{\lambda s}\right)^{2}\left(1-\rho_{\lambda s}\right)$ and $h_{+}$is given by Eq. (29) shown above.

To proceed further with the solution for $q_{\lambda}\left(K_{d}\right)$ and thus $\varepsilon_{\lambda}$ the source function $S_{\lambda}$ must be determined. For no scattering the source function is given as follows.

$$
S_{\lambda}(K)=n_{f}^{2} i_{b}(\lambda, T)=\frac{n_{f}^{2}}{\pi} e_{b}(\lambda, T)
$$

Since most of the selective emitter materials we have considered are single crystal in structure we assume that scattering is small compared to absorption and emission. Therefore, for the $\varepsilon_{\lambda}$ model we assume the no scattering source function given by 
Eq. (32) is a good approximation for the selective emitters we have considered. From Eq. (27) and using equation (32) in Eqs. (23) to (25) produces the following result for the spectral emittance when a linear temperature gradient (Eq. (6)) exists

$$
\varepsilon_{\lambda} \equiv \frac{q_{\lambda}\left(K_{d}\right)}{e_{b s}\left(\lambda, T_{s}\right)}=\frac{2 n_{f}^{2}\left(1-\rho_{\mathrm{f} 0}\right)}{D E N}\left\{\left[\frac{\varepsilon_{f s}}{n_{f}^{2}}+2 \rho_{f s} \Phi_{-}\left(K_{d}\right)\right] h_{-}+\bar{\Phi}_{+}\left(K_{d}\right) h_{+}-\bar{\Phi}_{M}\left(\frac{K_{d}}{\mu_{M}}\right) h_{M}\right\}
$$

no scattering with linear temperature gradient

Where,

$$
\begin{gathered}
\Phi_{+}\left(K_{d}\right)=\frac{\Phi_{+}\left(K_{d}\right)}{2 n_{f}^{2} e_{b s}\left(\lambda, T_{s}\right)}=K_{d}\left(e^{u}-1\right) \int_{0}^{1} \frac{E_{2}\left[K_{d}(1-v)\right]}{\exp \left[\frac{u}{1-v \Delta T}\right]-1} d v \\
\Phi_{-}\left(K_{d}\right)=\frac{\Phi_{-}\left(K_{d}\right)}{2 n_{f}^{2} e_{b s}\left(\lambda, T_{s}\right)}=K_{d}\left(e^{u}-1\right) \int_{0}^{1} \frac{E_{2}\left[K_{d} v\right]}{\exp \left[\frac{u}{1-v \Delta T}\right]-1} d v \\
\Phi_{M}\left(\frac{K_{d}}{\mu_{M}}\right)=\frac{\Phi_{M}\left(\frac{K_{d}}{\mu_{M}}\right)}{2 n_{f}^{2} e_{b s}\left(\lambda, T_{s}\right)}=\mu_{M} K_{d}\left(e^{u}-1\right) \int_{0}^{1} \frac{E_{2}\left[\frac{K_{d}}{\mu_{M}}(1-v)\right]}{\exp \left[\frac{u}{1-v \Delta T}\right]-1} d v
\end{gathered}
$$

Where $\Delta T$ is the temperature gradient given by Eq. (7) and

$$
\begin{gathered}
u=\frac{h c_{o}}{\lambda k T_{s}} \\
v=\frac{K}{K_{d}}=\frac{x}{d}
\end{gathered}
$$

From Eq. (33) we see that the emittance is made up of three parts. The coefficient

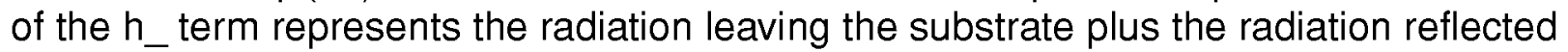
back into the film from the film-substrate interface. This part of the emittance decreases with increasing optical depth, $K_{d}$. The second part of the emittance, $\bar{\Phi}_{+} h_{+}$, represents the radiation emitted within the film and increases with increasing $\mathrm{K}_{\mathrm{d}}$. The last part of $\varepsilon_{\lambda}$ is the negative term, $-\bar{\Phi}_{M} h_{M}$, which represents the radiation with angle of incidence 
$\theta>\theta_{M}$ that is totally reflected back into the film at the film-vacuum interface. This part increases with increasing optical depth.

The integrals in Eqs. (34) to (36) can not be carried out in closed form. However, in the two limiting cases of $\mathrm{K}_{\mathrm{d}} \rightarrow \infty$ and $\mathrm{K}_{\mathrm{d}} \rightarrow 0$ the integrals can be evaluated. The $\mathrm{K}_{\mathrm{d}} \rightarrow \infty$ case approximates conditions that exist in the emission band of a rare earth selective emitter, while the $K_{d} \rightarrow 0$ case approximates conditions that exist in the region between the emission band and the long wavelength cutoff region. In most cases of interest for rare earth selective emitters the long wavelength cutoff region begins at $\lambda \approx 5 \mu \mathrm{m}$. Also, the substrate temperatures of interest are in the region $\mathrm{T}_{\mathrm{s}} \leq 2000 \mathrm{~K}$. As a result, the parameter, $\mathrm{u}$, (Eq. (37)) is greater than 1. Therefore, for $\mathrm{K}_{\mathrm{d}} \rightarrow \infty$ the following result is obtained. ${ }^{13}$

$$
\begin{array}{cc}
\lim _{\mathrm{d} \rightarrow \infty} \bar{\Phi}_{+}=\frac{1}{2} \mathrm{e}^{-\mathrm{u} \Delta \mathrm{T}} & \\
\lim _{\mathrm{K} \rightarrow \infty} \bar{\Phi}_{-}=\frac{1}{2} & \mathrm{u}>1 \\
\lim _{\mathrm{K}_{\mathrm{d}} \rightarrow \infty} \bar{\Phi}_{\mathrm{M}}=\frac{1}{2} \mu_{\mathrm{M}}^{2} \mathrm{e}^{-\mathrm{u} \Delta \mathrm{T}} &
\end{array}
$$

Also for $\mathrm{K}_{\mathrm{d}} \rightarrow \infty, \mathrm{E}_{3}(\infty)=0$ and therefore $\mathrm{h}_{+}=\mathrm{h}_{M}=1$ and $\mathrm{h}_{-}=0$ so that the spectral emittance is the following.

$$
\lim _{\mathrm{d} \rightarrow \infty} \varepsilon_{\lambda}=\mathrm{n}_{\mathrm{o}}^{2}\left(1-\rho_{\mathrm{f} 0}\right) \mathrm{e}^{-\mathrm{u} \Delta \mathrm{T}} \text { for } \mathrm{u}=\frac{\mathrm{hc_{0 }}}{\lambda \mathrm{kT} \mathrm{T}_{\mathrm{s}}}>1 \text { and no scattering }
$$

For a vacuum interface, $n_{0}=1$, and negligible temperature gradient, $\Delta T=0$, the usual result for an opaque body is obtained (Eq. (17)).

Now consider the case where $K_{d}=0$. In that case $E_{3}(0)=1 / 2$,

$\bar{\Phi}_{+}=\bar{\Phi}_{-}=\bar{\Phi}_{M}=0, h_{-}=\frac{1}{2}\left(1-\mu_{m}^{2}\right)=\frac{1}{2}\left(\frac{n_{o}}{n_{f}}\right)^{2}$ and the spectral emittance becomes the following.

$$
\varepsilon_{\lambda}=\frac{\left(1-\rho_{\mathrm{f} 0}\right)}{1-\rho_{\mathrm{fs}}\left[1-\left(\frac{\mathrm{n}_{\mathrm{o}}}{\mathrm{n}_{\mathrm{f}}}\right)^{2}\left(1-\rho_{\mathrm{f} 0}\right)\right]}\left(\frac{\mathrm{n}_{\mathrm{o}}}{\mathrm{n}_{\mathrm{f}}}\right)^{2} \varepsilon_{\mathrm{fs}} \quad u=\frac{h c_{\mathrm{o}}}{\lambda \mathrm{kT}}>1, \mathrm{~K}_{\mathrm{d}}=0 \text { and no scattering }
$$


In this case the emittance is determined by the substrate emittance and the reflectance that occurs at the vacuum-film and film-substrate interfaces. If $n_{0}=n_{f}\left(\therefore \rho_{f 0}=0\right)$ then Eq. (41) yields $\varepsilon_{\lambda}=\varepsilon_{\mathrm{fs}}=\varepsilon_{\text {os }}\left(\right.$ since $\left.n_{\mathrm{o}}=n_{\mathrm{f}}\right)$ as expected.

\section{Experimental Measurements}

The optical properties required to calculate the spectral emittance, $\varepsilon_{\lambda}$, with the emittance model are the indices of refraction and the extinction coefficient. Emissive performance of a selective emitter can be determined by measuring $\varepsilon_{\lambda}$ as a function of $\lambda$. Outlined below are the experimental procedures used to determine $n_{f}, \alpha_{f}$ and $\varepsilon_{\lambda}$.

\subsection{Index of Refraction and Extinction Coefficient Measurements}

Extinction coefficient and index of refraction are obtained from measured values of reflectance and transmittance. To cover the entire spectral region from the visible to approximately $11,000 \mathrm{~nm}$ two spectrophotometers were used, for $600 \leq \lambda \leq 2500 \mathrm{~nm}$ a Perkin Elmer Lambda 19 and for $2500 \leq \lambda \leq 11000 \mathrm{~nm}$ a Nicolet 750 FTIR.

The one-dimensional model shown in Fig. 3 was used to relate $\alpha_{\lambda}$ and $n_{f}$ to the measured transmittance, $T_{\lambda}$, and reflectance, $R_{\lambda}$. Assuming the reflectance, $\rho_{\lambda}$, at the two interfaces is the same then the overall reflectance, $R_{\lambda}$, transmittance, $T_{\lambda}$, and absorptance, $A_{\lambda}$, are the following (see Ref. 15, Ch. 19).

$$
\begin{gathered}
\mathrm{T}_{\lambda} \equiv \frac{\mathrm{q}_{04}}{\mathrm{q}_{\mathrm{i} 1}}=\frac{\tau_{\lambda}\left(1-\rho_{\lambda}\right)^{2}}{1-\rho_{\lambda}^{2} \tau_{\lambda}^{2}} \\
\mathrm{R}_{\lambda} \equiv \frac{\mathrm{q}_{01}}{\mathrm{q}_{\mathrm{i} 1}}=\rho_{\lambda}\left[1+\frac{\tau_{\lambda}^{2}\left(1-\rho_{\lambda}\right)^{2}}{1-\rho_{\lambda}^{2} \tau_{\lambda}^{2}}\right]=\rho_{\lambda}\left[1+\tau_{\lambda} \mathrm{T}_{\lambda}\right] \\
\mathrm{A}_{\lambda}=1-\mathrm{R}_{\lambda}-\mathrm{T}_{\lambda}
\end{gathered}
$$

Where $\tau_{\lambda}$ is the internal transmittance of the material. Assuming the material behaves according to Beer's law.

$$
\tau_{\lambda} \equiv \frac{q_{i 3}}{q_{\circ 2}}=\frac{q_{i 2}}{q_{03}}=e^{-\alpha_{\lambda} s}
$$

Where $S$ is the path length through the material. For a beam at normal incidence angle, as is the case for the spectrophotometers, $S=d$. Using Eqs. (42) and (43) the following result is obtained for $\tau_{\lambda}$. 


$$
\tau_{\lambda}=e^{-\alpha_{\lambda} d}=\frac{1}{2}\left\{\sqrt{\left[\frac{T_{\lambda}^{2}-\left(1-R_{\lambda}\right)^{2}}{T_{\lambda}}\right]^{2}+4}+\frac{1}{T_{\lambda}}\left[T_{\lambda}^{2}-\left(1-R_{\lambda}\right)^{2}\right]\right\}
$$

Where $R_{\lambda}$ and $T_{\lambda}$ are the spectrophotometer measured reflectance and transmittance. Equation (46) was used to obtain $\alpha_{\lambda}$ from the measured values of $R_{\lambda}, T_{\lambda}$ and $d$. The reflectance, $\rho_{\lambda}$, was obtained using Eq. (43) and $\tau_{\lambda}$ from Eq. (46). From $\rho_{\lambda}$ the index of refraction, $n_{f}$, was obtained using the expression for normal reflectance (Eq. (15b)) and $\mathrm{n}_{\mathrm{o}}=1$.

\subsection{Emittance Measurement}

Measurement of the spectral emittance is made using the experimental apparatus shown in Fig. 4. An atmospheric high temperature $\left(1700^{\circ} \mathrm{C}\right)$ furnace is used to heat the sample, which is mounted on the door of the furnace. The sample has a platinum $(\mathrm{Pt})$ foil substrate and a silicon carbide $(\mathrm{SiC})$ wafer behind the $\mathrm{Pt}$ foil. The $\mathrm{SiC}$ wafer radiatively couples well to the furnace because of its large absorptance thus reducing radial temperature gradients. A thermocouple to measure the substrate temperature, $T_{s}$, is mounted through a hole in the middle of the $\mathrm{SiC}$ wafer. The front surface temperature, $T_{f}$, is measured by a thermocouple mounted on a moveable probe.

The optical components and the front surface temperature probe are mounted on a moveable table. Emitted spectral intensity, $i_{\lambda s}$, from the sample is measured with a $1 / 8$ meter monochromator and three different detectors. For the visible region a $\mathrm{Si}$ detector is used. For $1000 \leq \lambda \leq 5000 \mathrm{~nm}$ an InSb detector is used and for $5000 \leq \lambda \leq 11000 \mathrm{~nm}$ a HgCdTe detector is used. Also 4 different monochromator gratings are used to span the full wavelength range. An aperture is used to limit the area viewed on the sample to approximately a $4 \mathrm{~mm}$ diameter. The intensity leaving the aperture is focused on the monochromator entrance by a reflecting concentrator. Emitted intensity is chopped to eliminate errors resulting from stray radiation entering the system downstream of the chopper. Upstream of the chopper, radiation emitted from the hot door insulation can enter the system by being reflected off the face of the sample. To reduce this stray light a Pt tube, which is mounted so as not to touch the hot insulation, is inserted through the hole in the door and up to the sample.

The system is calibrated by moving the optical system over to the blackbody, which is located exactly the same optical distance away from the monochromator as the sample. Thus when viewing the blackbody the current output, $J_{\lambda b}$, of photovoltaic detector is the following.

$$
J_{\lambda b}=R_{\lambda} F_{D s i b b}\left(\lambda, T_{b}\right)
$$

Where $R_{\lambda}$ is the response (amp/watt) of the detector, $F_{D s}$ is the view factor of the detector to the sample and $\mathrm{i}_{b b}\left(\lambda, T_{b}\right)$ is the blackbody intensity at temperature, $T_{b}$. When 
viewing the sample the detector output is the following.

$$
\mathrm{J}_{\lambda s}=\mathrm{R}_{\lambda} \mathrm{F}_{\mathrm{Ds}} \mathrm{i}_{\lambda s}\left(\lambda, \mathrm{T}_{\mathrm{s}}\right)
$$

Combining Eqs. (47) and (48) and using the definition of spectral emittance produces the following result.

$$
\varepsilon_{\lambda n} \equiv \frac{i_{\lambda s}\left(\lambda, T_{s}\right)}{i_{b s}\left(\lambda, T_{s}\right)}=\frac{J_{\lambda s}}{J_{\lambda b}} \frac{i_{b b}\left(\lambda, T_{b}\right)}{i_{b s}\left(\lambda, T_{s}\right)}
$$

Notice that $\varepsilon_{\lambda_{n}}$ is different than the definition for $\varepsilon_{\lambda}$ given by Eq. (8). In the experiment the intensity $i_{\lambda s}$ that is measured results from radiation that is emitted in the direction normal to the surface. Thus $\varepsilon_{\lambda n}$ is really the normal spectral emittance. However, in most cases $i_{\lambda s}$ is nearly independent of angle, which was assumed in the emittance model, so that $q_{\lambda}(d)=\pi i_{\lambda s}$ and thus $\varepsilon_{\lambda n}=\varepsilon_{\lambda}$.

In deriving Eq. (49) we assumed the detector response $R_{\lambda}$ is a function of $\lambda$ only and is independent of intensity, $\mathrm{i}_{\lambda}$. This is a good assumption for photovoltaic detectors but not good for photoconductive type detectors.

\section{Emissive Property Results For Rare Earth Aluminum Garnets}

Up until the present time our efforts have been directed at rare earth doped YAG and rare earth aluminum garnets in single crystal form. Therefore, the experimental results that follow are for Er and Tm single crystal aluminum garnets. Also, results for garnets with both $\mathrm{Er}$ and Ho are presented.

\subsection{Importance of Temperature Gradient on Emissive Performance}

Since radiation is strongly dependent on temperature there will be a significant effect of temperature gradient, $\Delta \mathrm{T}$, on the spectral emittance. This can be shown by using the spectral emittance model of the previous section. Using the extinction coefficient data for erbium aluminum garnet, $\mathrm{Er}_{3} \mathrm{Al}_{5} \mathrm{O}_{12}$, shown in Fig. 1, $\varepsilon_{\lambda}$ (Eq. (33)) was calculated for an emitter with a platinum substrate, a thickness $d=0.63 \mathrm{~mm}$ and a substrate temperature, $\mathrm{T}_{\mathrm{s}}=1635 \mathrm{~K}$. Results for the platinum index of refraction were obtained from Ref. 16. The $\varepsilon_{\lambda}$ results for $800 \leq \lambda \leq 2000 \mathrm{~nm}$ are shown in Fig. 5 for $\Delta \mathrm{T}=0$ and $\Delta \mathrm{T}=0.08$. As can be seen, in the emission bands centered at $\lambda \approx 1000 \mathrm{~nm}$ and $\lambda \approx 1500 \mathrm{~nm}$, where the extinction coefficient is large, the spectral emittance is greatly reduced in going from $\Delta T=0$ to $\Delta T=0.08$. Outside the emission bands, where the extinction coefficient is much smaller, the spectral emittance is not greatly effected by $\Delta \mathrm{T}$.

Obviously $\Delta T$ can be reduced by decreasing the thickness, $d$. However, decreasing $\mathrm{d}$ also reduces the optical depth, $\mathrm{K}_{\mathrm{d}}=\alpha_{\lambda} \mathrm{d}$, which will result in reduced $\varepsilon_{\lambda}$. Thus varying $\mathrm{d}$ produces counteracting effects on $\varepsilon_{\lambda}$. Decreasing $\mathrm{d}$ will reduce $\Delta \mathrm{T}$, which 
will increase $\varepsilon_{\lambda}$. But decreasing $d$ will also reduce $K_{d}$, which will decrease $\varepsilon_{\lambda}$. As a result, there will be an optimum thickness, $d$, to obtain a maximum $\varepsilon_{\lambda}$.

\subsection{Effect of Doping Level on Extinction Coefficient of $\operatorname{Er}_{x} \mathrm{Y}_{3-\mathrm{x}} \mathrm{Al}_{5} \mathrm{O}_{12}$}

The extinction coefficient, $\alpha_{\lambda}$, is the critical optical property for determining spectral emittance, $\varepsilon_{\lambda}$, since the optical depth, $\mathrm{K}_{\mathrm{d}}=\alpha_{\lambda} \mathrm{d}$, is directly proportional to $\alpha_{\lambda}$. Large $\alpha_{\lambda}$ will result in large $\varepsilon_{\lambda}$. Therefore, to evaluate the effect of doping level on the emittance of erbium doped YAG we measured the extinction coefficient for a series of doping levels. The results of these measurements are shown in Fig. 6 for the wavelength range $800 \leq \lambda \leq 2000 \mathrm{~nm}$.

As Fig. 6 shows the extinction coefficient is a monotonically increasing function of the Er doping level. The maximum extinction coefficients in the emission bands double in going from $\mathrm{Er}_{1.5} \mathrm{Y}_{1.5} \mathrm{Al}_{5} \mathrm{O}_{12}$ to pure erbium aluminum garnet, $\mathrm{Er}_{3} \mathrm{Al}_{5} \mathrm{O}_{12}$. However, a doubling of $\alpha_{\lambda}$ in an emission band where $\alpha_{\lambda}$ is already large does not translate into a doubling of $\varepsilon_{\lambda}$. For large $\alpha_{\lambda}$ and thus large $\mathrm{K}_{\mathrm{d}}$ the emittance is approximated by Eq. (40) which shows that $\varepsilon_{\lambda}$ is independent of $\alpha_{\lambda}$. The benefit of a large extinction coefficient is that the thickness, $d$, can be reduced while still maintaining a large optical depth $\left(K_{d} \geq 1\right)$. Thus the smaller $d$ will result in a smaller temperature gradient which in turn will increase $\varepsilon_{\lambda}$, as Eq. (40) indicates.

The effect of doping level on extinction coefficient has been established only for $\mathrm{Er}_{\mathrm{x}} \mathrm{Y}_{3-\mathrm{x}} \mathrm{Al}_{5} \mathrm{O}_{12}$. However, due to their similar atomic structure we expect the same increase in $\alpha_{\lambda}$ with increasing doping level for $\mathrm{Ho}_{x} \mathrm{Y}_{3-\mathrm{x}} \mathrm{Al}_{5} \mathrm{O}_{12}$ and $\mathrm{Tm}_{\mathrm{x}} \mathrm{Y}_{3-\mathrm{x}} \mathrm{Al}_{5} \mathrm{O}_{12}$. Panitz ${ }^{17}$ has found similar results for $Y b$ doping of $Y A G$.

\subsection{Spectral Emittance of $\mathrm{Er}_{3} \mathrm{Al}_{5} \mathrm{O}_{12}, \mathrm{Tm}_{3} \mathrm{Al}_{5} \mathrm{O}_{12}, \mathrm{Er}_{0.3} \mathrm{Ho}_{2.7} \mathrm{Al}_{5} \mathrm{O}_{12}$ and $\mathrm{Er}_{1.5} \mathrm{Ho}_{1.5} \mathrm{Al}_{5} \mathrm{O}_{12}$}

Figure 7 compares the measured and calculated spectral emittance of erbium aluminum garnet, $\mathrm{Er}_{3} \mathrm{Al}_{5} \mathrm{O}_{12}$, for a sample of thickness, $\mathrm{d}=0.63 \mathrm{~mm}$, with a $\mathrm{Pt}$ foil substrate. The substrate temperature was $T_{\mathrm{s}}=1635 \mathrm{~K}$ and the measured temperature gradient was $\Delta T=0.08$. Figure 7 (a) shows the wavelength region $600 \leq \lambda \leq 10,000 \mathrm{~nm}$ while Fig. 7(b) shows an expanded view of the emission band region $800 \leq \lambda \leq 2000 \mathrm{~nm}$. Er has four emission bands associated with electronic transitions from the first 4 excited state manifolds to the ground state. The most intense band centered at $\lambda \approx 1500 \mathrm{~nm}$ results from transitions from the first excited state manifold $\left({ }^{4} I_{13 / 2} \rightarrow{ }^{4} I_{15 / 2}\right)$. The other three bands centered at $\lambda \approx 1000 \mathrm{~nm}, 800 \mathrm{~nm}$ and $640 \mathrm{~nm}$ result from transitions of the next three excited state manifolds $\left({ }^{4} I_{11 / 2} \rightarrow{ }^{4} I_{15 / 2},{ }^{4} I_{9 / 2} \rightarrow{ }^{4} I_{15 / 2}\right.$ and $\left.{ }^{4} F_{9 / 2} \rightarrow{ }^{4} I_{15 / 2}\right)$. The large emittance in the region $\lambda \geq 5000 \mathrm{~nm}$ results from the vibrational modes of the crystal lattice. As pointed out in the Introduction, this long wavelength cutoff region occurs for most all high temperature ceramic materials.

There is good agreement between the measured and calculated (Eq. (33)) spectral emittance except for the region $1800 \leq \lambda \leq 6000 \mathrm{~nm}$. In the region $1800 \leq \lambda \leq 4000 \mathrm{~nm}$ where the extinction coefficient is small the main contribution to the emittance comes from the Pt substrate. Error in the measured extinction coefficient is the reason the calculated $\varepsilon_{\lambda}$ is larger than the measured value in the 
$1800 \leq \lambda \leq 4000 \mathrm{~nm}$ region. In this region where $\mathrm{Er}_{3} \mathrm{Al}_{5} \mathrm{O}_{12}$ absorption, $\mathrm{A}_{\lambda}=1-\mathrm{T}_{\lambda}-\mathrm{R}_{\lambda}$, is small means that $T_{\lambda} \approx 1-R_{\lambda}$. Thus, referring to Eq. (46) we see that if $T_{\lambda} \approx 1-R_{\lambda}$ the quantity $T_{\lambda}^{2}-\left(1-R_{\lambda}\right)^{2}$ can have considerable numerical error which then results in $\alpha_{\lambda}$ being overestimated in the $1800 \leq \lambda \leq 4000 \mathrm{~nm}$ region.

For the region $4000 \leq \lambda \leq 6000 \mathrm{~nm}$ the vibrational modes of the crystal lattice are the primary source of the emission. The extinction coefficient was measured at room temperature. Therefore, the calculated $\varepsilon_{\lambda}$ for $4000 \leq \lambda \leq 6000 \mathrm{~nm}$ corresponds to room temperature conditions. Since the calculated $\varepsilon_{\lambda}$ is less than the experimental $\varepsilon_{\lambda}$ in the $4000 \leq \lambda \leq 6000 \mathrm{~nm}$ region we conclude that the crystal lattice structure is changing with temperature such that higher energy (shorter wavelength) modes exist. These new modes produce the increase in extinction coefficient in the $4000 \leq \lambda \leq 6000 \mathrm{~nm}$ region. In the emission band region, $600 \leq \lambda \leq 1800 \mathrm{~nm}$ electronic transitions of the Er ions account for the radiation. Therefore, widening of the emission bands is the expected effect for increasing temperature rather than increasing extinction coefficient. This conclusion is substantiated since there is good agreement between experimental and calculated $\varepsilon_{\lambda}$ for $600 \leq \lambda \leq 1800 \mathrm{~nm}$ with the experimental emission bands being somewhat broader. The resolution of the extinction coefficient data was much greater than experimental $\varepsilon_{\lambda}$ data. As a result, the calculated $\varepsilon_{\lambda}$ shows more structure in the emission bands.

As a measure of the effectiveness of $\mathrm{Er}_{3} \mathrm{Al}_{5} \mathrm{O}_{12}$ as a selective emitter we define the emitter efficiency as follows.

$$
\eta_{\mathrm{E}} \equiv \frac{\text { useful radiated power }}{\text { total radiated power }}=\frac{\int_{0}^{\lambda_{\ell}} \mathrm{q}_{\lambda}(\mathrm{d}) \mathrm{d} \lambda}{\int_{0}^{\infty} \mathrm{q}_{\lambda}(\mathrm{d}) \mathrm{d} \lambda}=\frac{\int_{0}^{\lambda_{\ell}} \varepsilon_{\lambda} \mathrm{e}_{\mathrm{bs}}\left(\lambda, \mathrm{T}_{\mathrm{s}}\right) \mathrm{d} \lambda}{\int_{0}^{\infty} \varepsilon_{\lambda} e_{\mathrm{bs}}\left(\lambda, \mathrm{T}_{\mathrm{s}}\right) \mathrm{d} \lambda}
$$

The numerator is the power radiated in the wavelength region $0 \leq \lambda \leq \lambda_{\ell}$, where $\lambda_{\ell}$ is the wavelength at the end of the main emission band $\left(\lambda_{\ell}=1650 \mathrm{~nm}\right.$ for $\left.\operatorname{Er}_{3} \mathrm{Al}_{5} \mathrm{O}_{12}\right)$. The denominator is the total radiated power. As shown in Fig. 7 the calculated efficiency is $\left.\eta_{E}\right|_{c a l}=0.20$ and the experimental efficiency is $\left.\eta_{E}\right|_{\exp }=0.21$. The theoretical efficiency is smaller because $\left.\varepsilon_{\lambda}\right|_{\text {cal }}$ is too large in the $1800 \leq \lambda \leq 4000 \mathrm{~nm}$ region. As Eq. (33) shows, $\varepsilon_{\lambda}$ is not a function of $T_{s}$ but is a function of $\Delta T$ for the no scattering and linear temperature gradient approximations. However, the blackbody emissive power, $e_{b s}\left(\lambda, T_{s}\right)$, is a sensitive function of $T_{s}$. As a result $\eta_{E}$ is also a sensitive function of $T_{s}$. For $\mathrm{d}=0.3 \mathrm{~mm}, \mathrm{~T}_{\mathrm{s}}=1234{ }^{\circ} \mathrm{K}$ and $\Delta \mathrm{T}=0.094$ the measured efficiency is reduced to $\left.\eta_{E}\right|_{\exp }=0.065$.

Figure 8 compares calculated and measured values of $\varepsilon_{\lambda}$ for $\mathrm{Tm}_{3} \mathrm{Al}_{5} \mathrm{O}_{12}$ on a Pt substrate with $d=0.5 \mathrm{~mm}$. The substrate temperature was $T_{s}=1700 \mathrm{~K}$ and $\Delta T=0.11$. Similar to $\mathrm{Er}_{3} \mathrm{Al}_{5} \mathrm{O}_{12}, \mathrm{Tm}_{3} \mathrm{Al}_{5} \mathrm{O}_{12}$ has emission bands that originate from transitions to the ground state from the 4 lowest excited states; ${ }^{3} \mathrm{~F}_{4} \rightarrow{ }^{3} \mathrm{H}_{6}$ centered at $\lambda \approx 1700 \mathrm{~nm}$, ${ }^{3} \mathrm{H}_{5} \rightarrow{ }^{3} \mathrm{H}_{6}$ centered at $\lambda \approx 1200 \mathrm{~nm},{ }^{3} \mathrm{H}_{4} \rightarrow{ }^{3} \mathrm{H}_{6}$ centered at $\lambda \approx 800 \mathrm{~nm}$ and ${ }^{3} \mathrm{H}_{3} \rightarrow{ }^{3} \mathrm{H}_{6}$ centered at $\lambda \approx 700 \mathrm{~nm}$. The first excited state to ground state transition $\left({ }^{3} \mathrm{~F}_{4} \rightarrow{ }^{3} \mathrm{H}_{6}\right)$ has the largest intensity. Also similar to $\mathrm{Er}_{3} \mathrm{Al}_{5} \mathrm{O}_{12}$, the long wavelength region of large emittance begins at $\lambda \approx 5000 \mathrm{~nm}$. Similar to $\mathrm{Er}_{3} \mathrm{Al}_{5} \mathrm{O}_{12}$, there is good agreement between the experimental and theoretical emittance in the emission band regions. Also, 
because of experimental error in the extinction coefficient for the region $2000<\lambda<5000 \mathrm{~nm}$ the theoretical emittance has large fluctuations, as well as, being too large. For $\mathrm{Tm}_{3} \mathrm{Al}_{5} \mathrm{O}_{12}$ the measured emitter efficiency using $\lambda_{\ell}=1900 \mathrm{~nm}$ in Eq. (50) is $\eta_{E} l_{\text {exp }}=0.38$ compared to $\eta_{E} I_{\text {cal }}=0.31$ for the sample in Fig. 8. Since $T_{s}$ is nearly the same for both the $\mathrm{Er}_{3} \mathrm{Al}_{5} \mathrm{O}_{12}$ and $\mathrm{Tm}_{3} \mathrm{Al}_{5} \mathrm{O}_{12}$ sample we can compare their efficiencies. The larger $\eta_{E}$ for $\mathrm{Tm}_{3} \mathrm{Al}_{5} \mathrm{O}_{12}$ compared to $\eta_{\mathrm{E}}$ for $\mathrm{Er}_{3} \mathrm{Al}_{5} \mathrm{O}_{12}$ results for two reasons. First of all, even though $\varepsilon_{\lambda}$ in the four emission bands is nearly the same for both $\mathrm{Tm}$ and $\mathrm{Er}$ the widths of the Tm bands are greater. Second, the integration limit, $\lambda_{\ell}$, in Eq. (50) is larger for $\operatorname{Tm}\left(\lambda_{\ell}=1900 \mathrm{~nm}\right)$ than $\operatorname{Er}\left(\lambda_{\ell}=1650 \mathrm{~nm}\right)$. At $\mathrm{T}_{\mathrm{s}}=1262 \mathrm{~K}$ and $\Delta \mathrm{T}=0.062$ the measured efficiency is $\eta_{E} l_{\text {exp }}=0.19$ for the sample in Fig. 8.

One possible method for increasing the useful power (numerator of Eq. (50)) is by doping the host material with more than one rare earth. To investigate this approach we measured the spectral emittance and efficiency of erbium holmium aluminum garnet $\left(\mathrm{Er}_{\mathrm{x}} \mathrm{Ho}_{3-\mathrm{x}} \mathrm{Al}_{5} \mathrm{O}_{12}\right.$ ) at two different doping levels; $\mathrm{Er}_{0.3} \mathrm{Ho}_{2.7} \mathrm{Al}_{5} \mathrm{O}_{12}$ and $\mathrm{Er}_{1.5} \mathrm{Ho}_{1.5} \mathrm{Al}_{5} \mathrm{O}_{12}$. The experimental and theoretical results for $\mathrm{Er}_{0.3} \mathrm{HO}_{2.7} \mathrm{Al}_{5} \mathrm{O}_{12}$ of thickness, $\mathrm{d}=0.55 \mathrm{~mm}$, with $\mathrm{Pt}$ foil substrate are shown in Fig. 9. In this case the substrate temperature was $\mathrm{T}_{\mathrm{s}}=1298 \mathrm{~K}$ and the temperature gradient was $\Delta \mathrm{T}=0.080$. Notice there is good agreement between measured and calculated $\varepsilon_{\lambda}$. Since the doping level of Er was much lower than Ho the four emission bands of $\operatorname{Er}$ at $\lambda \approx 1500,1000,800$, and $640 \mathrm{~nm}$ are smaller than the Ho emission bands resulting from transitions from the four lowest excited states. The main Ho emission band results from transitions from the first excited state manifold to ground state, ${ }^{5} \mathrm{I}_{7} \rightarrow{ }^{5} \mathrm{I}_{8}$, and is centered at $\lambda \approx 2000 \mathrm{~nm}$. Transitions from the second excited state manifold, ${ }^{5} \mathrm{I}_{6} \rightarrow{ }^{5} \mathrm{I}_{8}$, produce the band centered at $\lambda \approx 1100 \mathrm{~nm}$. Transitions from the third excited state manifold, ${ }^{5} \mathrm{I}_{5} \rightarrow{ }^{5} \mathrm{I}_{8}$, produce the band centered at $\lambda \approx 890 \mathrm{~nm}$. And finally, transitions from the fourth excited state manifold, ${ }^{5} \mathrm{I}_{4} \rightarrow{ }^{5} \mathrm{I}_{8}$, produce the band at $\lambda \approx 750 \mathrm{~nm}$. The three shorter wavelength bands of $\mathrm{Er}$ and $\mathrm{Ho}$ are close together so that they merge together in the spectral emittance. Using $\lambda_{\ell}=2150 \mathrm{~nm}$ in Eq. (50), the experimental and calculated efficiencies are 0.27 for the data in Fig. 9.

When the doping levels of $\mathrm{Er}$ and $\mathrm{Ho}$ are the same $\left(\mathrm{Er}_{1.5} \mathrm{Ho}_{1.5} \mathrm{Al}_{5} \mathrm{O}_{12}\right)$ the spectral emittance results are those shown in Fig. 10 for a sample of thickness, $\mathrm{d}=0.65 \mathrm{~mm}$, and Pt foil substrate. In this case, the substrate temperature was $\mathrm{T}_{\mathrm{s}}=1218 \mathrm{~K}$ and the temperature gradient was $\Delta \mathrm{T}=0.074$. The $\mathrm{Er}$ bands have increased $\varepsilon_{\lambda}$ while the $\mathrm{Ho}$ bands have decreased $\varepsilon_{\lambda}$ compared to the $\mathrm{Er}_{0.3} \mathrm{Ho}_{2.7} \mathrm{Al}_{5} \mathrm{O}_{12}$ results (Fig. 9). Again there is good agreement between $\varepsilon_{\lambda} l_{\text {cal }}$ and $\varepsilon_{\lambda} l_{\text {exp. }}$. The measured efficiency is $\eta_{E} l_{\exp }=0.23$ compared to $\left.\eta_{E}\right|_{\text {cal }}=0.20$. Since $T_{S}$ and $\Delta T$ are nearly the same for $\mathrm{Er}_{0.3} \mathrm{Ho}_{2.7} \mathrm{Al}_{5} \mathrm{O}_{12}$ and $\mathrm{Er}_{1.5} \mathrm{Ho}_{1.5} \mathrm{Al}_{5} \mathrm{O}_{12}$ in Figs. 9 and 10, we can make a valid comparison of efficiencies. Since $\eta_{E}$ is larger for $\mathrm{Er}_{0.3} \mathrm{Ho}_{2.7} \mathrm{Al}_{5} \mathrm{O}_{12}$, we conclude that it is a better selective emitter than $\mathrm{Er}_{1.5} \mathrm{Ho}_{1.5} \mathrm{Al}_{5} \mathrm{O}_{12}$.

\section{Conclusion}

Rare earth ions in high temperature host materials emit in several narrow bands in the near infrared and the visible spectrum. A spectral emittance model, where optical depth is the key variable, has been developed for these rare earth selective emitters. 
There are many possible host materials although we have investigated only rare earth aluminum garnets of Er, Ho and Tm. Experimental measurements of the extinction coefficients and spectral emittances of these garnets have been made. The experimental and theoretical spectral emittance results are in good agreement. Maximum spectral emittances of 0.6 to 0.8 occur in the emission bands. At $\lambda>5000 \mathrm{~nm}$ all these materials have large emittance $\left(\varepsilon_{\lambda}>0.8\right)$ as a result of emission from the vibrational modes of the crystal structures. Small temperature gradients $(\Delta T<0.1)$ across the film emitters result in significant reductions in spectral emittance. Because spectral emittance increases with optical depth but decreases with temperature gradient there is an optimum film thickness for maximum emittance. Emitter efficiency is a sensitive function of temperature. For thulium aluminum garnet $\left(\operatorname{Tm}_{3} \mathrm{Al}_{5} \mathrm{O}_{12}\right)$ the efficiency at $T_{s}=1262 \mathrm{~K}$ for film thickness, $d=0.5 \mathrm{~mm}$, and temperature gradient, $\Delta T=0.062$ is $\eta_{E} l_{\text {exp }}=0.19$ and at $T_{S}=1700 \mathrm{~K}$ with $\Delta T=0.11$ the efficiency is $\eta_{E} l_{\exp }=0.38$.

\section{References}

1. Dieke, G.H., Spectra and Energy Levels of Rare Earth lons in Crystals, Interscience, New York, 1968.

2. Guazzoni, G.E., Appl. Spectra. 26, 60, 1972.

3. Nelson, R.E., in Proceedings of the 32nd International Power Sources Symposium (Electronchemical Society, Pennington, NJ, 1986), pp. 95-101.

4. Parent, C.R. and Nelson, R.E., in Proceedings of the 21st Intersociety Energy Conversion (American Chemical Society, Washington, D.C., 1986), vol. 2, pp. 1314-1317.

5. Chubb, D.L., in Proceedings of the 21st Photovoltaic Specialists Conference (IEEE, New York, 1990), pp. 1326-1333; also NASA TM-103290.

6. Chubb, D.L., and Lowe, R.A., J. Appl. Phys., 74, 5687 (1993).

7. Lowe, R.A., Chubb, D.L., Farmer, S.C., and Good, B.S., Appl. Phys. Lett. 64, 3551, 1994.

8. Lowe, R.A., Chubb, D.L., and Good, B.S., in Proceedings of the First NREL Conference on Thermophotovoltaic Generation of Electricity, (American Institute of Physics Conference Proceedings 321, 1994), pp. 291-297.

9. Lowe, R.A., Chubb, D.L., and Good, B.S, in Proceedings of the First World Conference on Photovoltaic Energy Conversion, (IEEE, 1995).

10. Lowe, R.A., Good, B.S., and Chubb, D.L., in Proceedings of 30th Intersociety Energy Conversion Engineering Conference (IECEC), (American Society of Mechanical Engineers, 1995), vol. 2, pp. 511-515.

11. Chubb, D.L., Lowe, R.A., and Good, B.S., in Proceedings of The First NREL Conference on Thermophotovoltaic Generation of Electricity, (American Institute of Physics Conference Proceedings 321, 1994), pp. 229-244.

12. Good, B.S., Chubb, D.L., and Lowe, R.A., in Proceedings of The First NREL Conference on Thermophotovoltaic Generation of Electricity, (American Institute of Physics Conference Proceedings 321, 1994), pp. 263-275. 
13. Chubb, D.L., Good, B.S., Clark, E.B. and Chen, Z., Effect of Temperature Gradient on Thick Film Selective Emitter Emittance, presented at The Third NREL Conference on Thermphotovoltaic Generation of Electricity, AIP Conference Proceedings 401, 1997.

14. Good, B.S. and Chubb, D.L., in Proceedings of the Fourth NREL Conference on Thermophotovoltaic Generation of Electricity (to be published as American Institute of Physics (AIP) Conference Proceedings).

15. Siegel, R. and Howell, J.R., Thermal Radiation Heat Transfer, 2nd edition, Washington, DC, Hemisphere, 1981, Chs. 4, 14.

16. Lide, D.R., (Ed.), CRC Handbook of Chemistry and Physics, 71st ed., CRC Press, 1990.

17. Panitz, J.-C., Schubnell, M., Durisch, W., and Geiger, F., "Influence of Ytterbium Concentration on the Emissive Properties of $\mathrm{Yb}: \mathrm{YAG}$ and $\mathrm{Yb}: \mathrm{Y}_{2} \mathrm{O}_{3}$," presented at The Third NREL Conference on Thermphotovoltaic Generation of Electricity, AIP Conference Proceedings 401, 1997.

TABLE I._POSSIBLE HIGH TEMPERATURE HOST MATERIALS FOR RARE EARTHS $(\mathrm{Re})$

\begin{tabular}{|c|c|c|}
\hline Host material & Chemical formula & $\begin{array}{c}\text { Melting point, }{ }^{\circ} \mathrm{C} \\
\text { of host } \\
\text { (Ref. 16) }\end{array}$ \\
\hline $\begin{array}{l}\text { Pure rare } \\
\text { earth oxide }\end{array}$ & $\mathrm{Re}_{2} \mathrm{O}_{3}$ & $>2200$ \\
\hline $\begin{array}{l}\text { Yttrium aluminum } \\
\text { garnet (YAG) }\end{array}$ & $\begin{array}{c}\mathrm{Re}_{x} \mathrm{Y}_{3-x} \mathrm{Al}_{5} \mathrm{O}_{12} \\
0 \leq x \leq 3\end{array}$ & 1930 \\
\hline $\begin{array}{l}\text { Gadolinium gallium } \\
\text { garnet (GGG) }\end{array}$ & $\underset{0 \leq x \leq 3}{\operatorname{Re}_{x} \mathrm{Gd}_{3-x} \mathrm{Ga}_{5} \mathrm{O}_{12}}$ & 1750 \\
\hline Spinel & $\underset{0 \leq x \leq 1}{R e_{x} M_{1-x} A_{2} \mathrm{O}_{4}}$ & $\approx 2100$ \\
\hline Zirconia & $\begin{array}{c}\mathrm{Re}_{\mathrm{x}} \mathrm{Zr}_{1-1} \mathrm{O}_{2} \\
0 \leq \mathrm{x} \leq 1\end{array}$ & $\approx 2700$ \\
\hline Yttria & $\begin{array}{c}\mathrm{Re}_{\mathrm{x}} \mathrm{Y}_{2-\mathrm{x}} \mathrm{O}_{3} \\
0 \leq x \leq 2\end{array}$ & 2400 \\
\hline
\end{tabular}




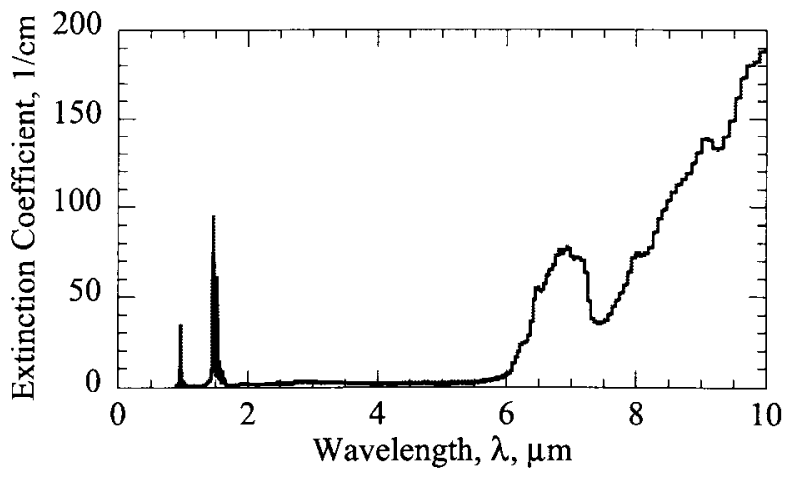

Fig. 1. Extinction coefficient for erbium aluminum garnet $\left(\mathrm{Er}_{3} \mathrm{Al}_{5} \mathrm{O}_{12}\right)$.

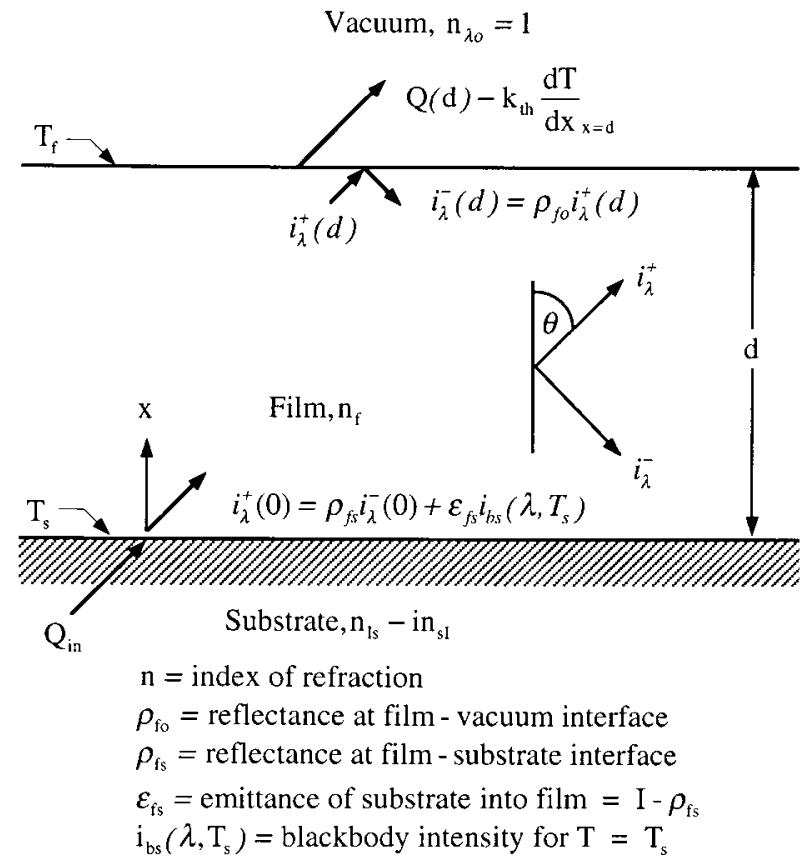

Fig. 2. Schematic diagram of film emittance model. 


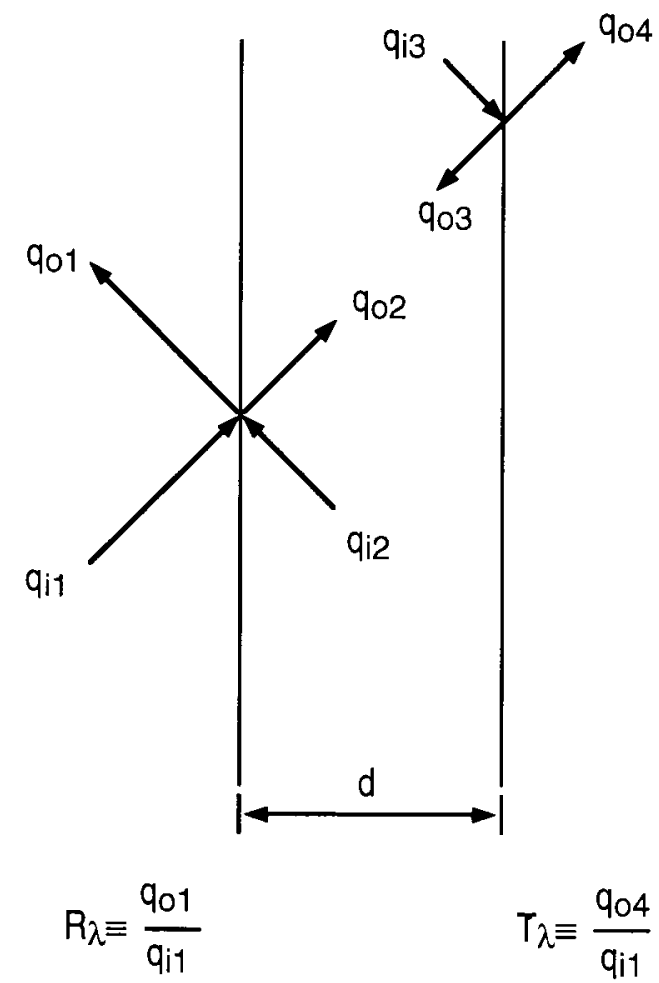

Fig. 3. Model for calculating overall reflectance, $\mathrm{R}_{\boldsymbol{\lambda}}$, and transmittance, $\mathrm{T}_{\boldsymbol{\lambda}}$. 


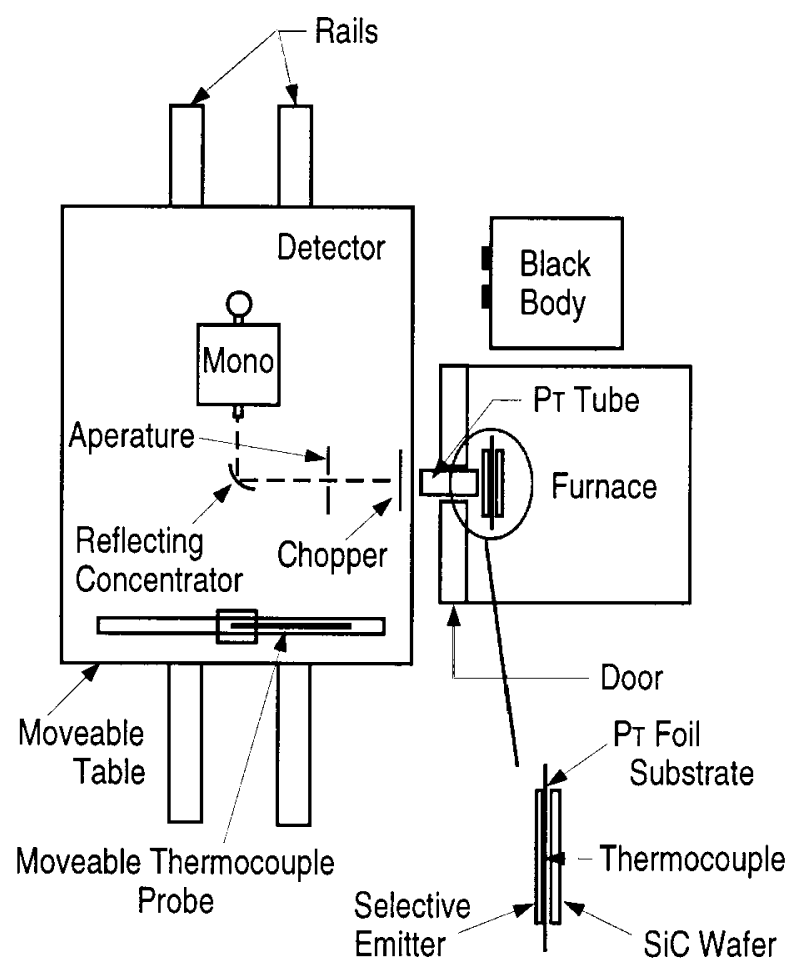

Fig. 4. Experimental emittance measurement apparatus.

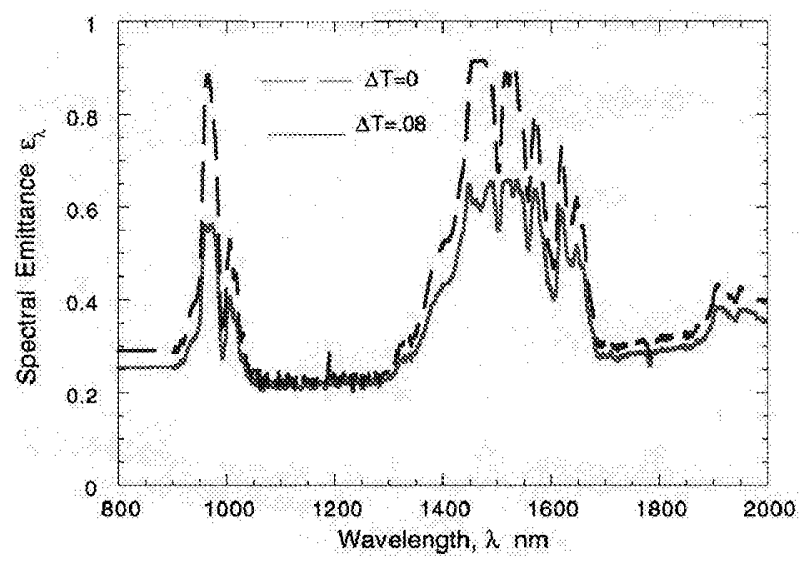

Fig. 5. Effect of temperature gradient on spectral emittance of $\mathrm{Er}_{3} \mathrm{Al}_{5} \mathrm{O}_{12}$ with platinum substrate for $\mathrm{T}_{\mathrm{S}}=1635 \mathrm{~K}$ and $\mathrm{d}=0.63 \mathrm{~mm}$. 

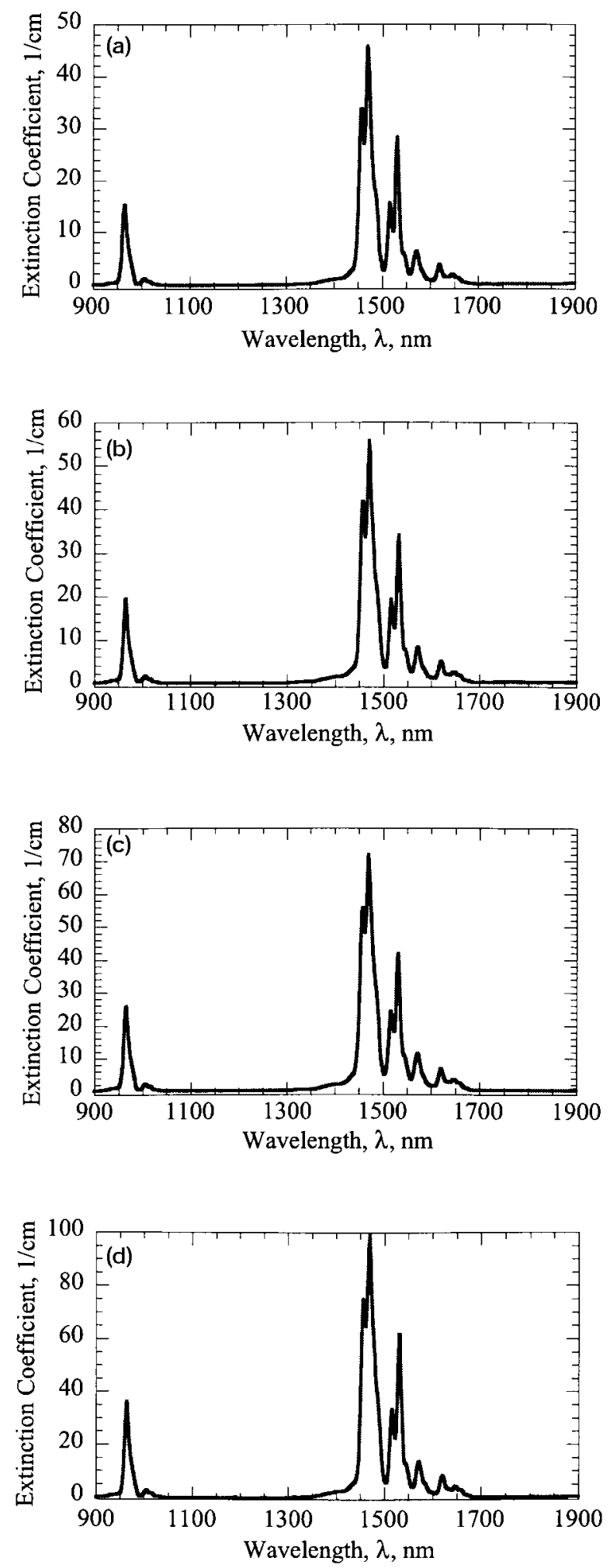

Fig. 6. Effect on extinction coefficient of Er-doping level in YAG. (a) Extinction coefficient for $\mathrm{Er}_{1.5} \mathrm{Y}_{1.5} \mathrm{Al}_{5} \mathrm{O}_{12}$. (b) Extinction coefficient for $\mathrm{Er}_{1.8} \mathrm{Y}_{1.2} \mathrm{Al}_{5} \mathrm{O}_{12}$. (c) Extinction coefficient for $\mathrm{Er}_{2.7} \mathrm{Y}_{0.3} \mathrm{Al}_{5} \mathrm{O}_{12}$. (d) Extinction coefficient for $\mathrm{Er}_{3} \mathrm{Al}_{5} \mathrm{O}_{12}$. 

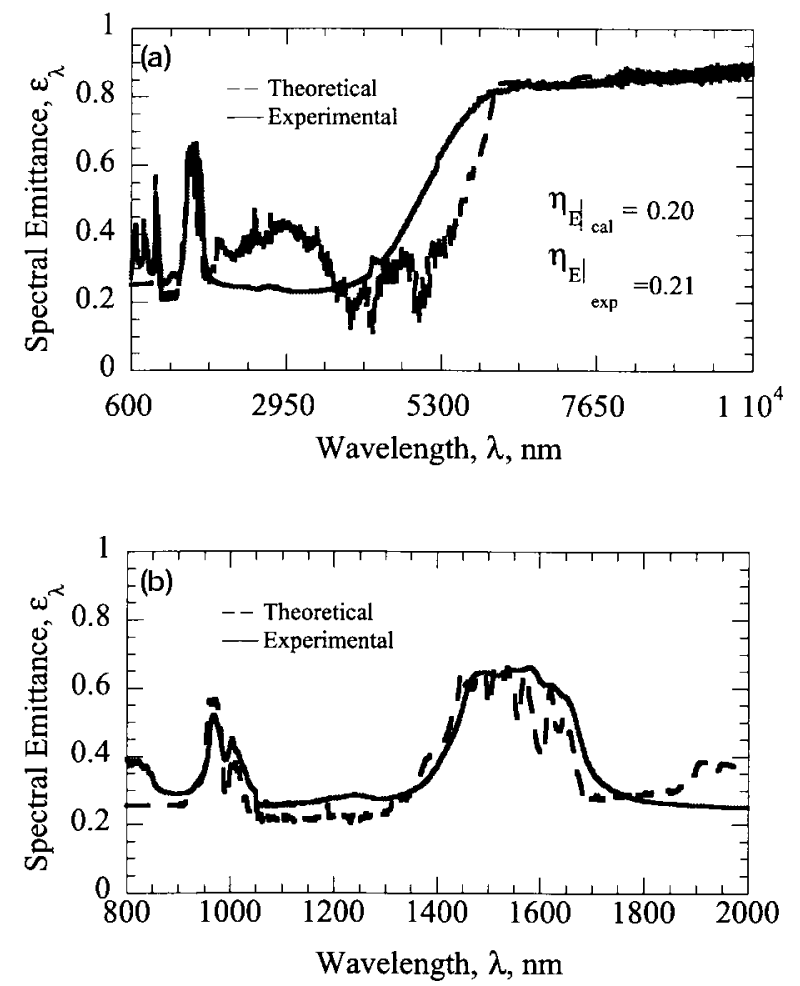

Fig. 7. Comparison of experimental and calculated spectral emittance of Erbium aluminum garnet $\left(\mathrm{Er}_{3} \mathrm{Al}_{5} \mathrm{O}_{12}\right)$ with platinum substrate. Thickness, $\mathrm{d}=0.63 \mathrm{~mm}$, substrate temperature, $\mathrm{T}_{\mathrm{S}}=1635 \mathrm{~K}$, front face temperature, $\mathrm{T}_{\mathrm{f}}=1503 \mathrm{~K}, \Delta \mathrm{T}=0.0807$. (a) $600<\boldsymbol{\lambda}<10,000 \mathrm{~nm}$. (b) $800<\boldsymbol{\lambda}<2000 \mathrm{~nm}$. 

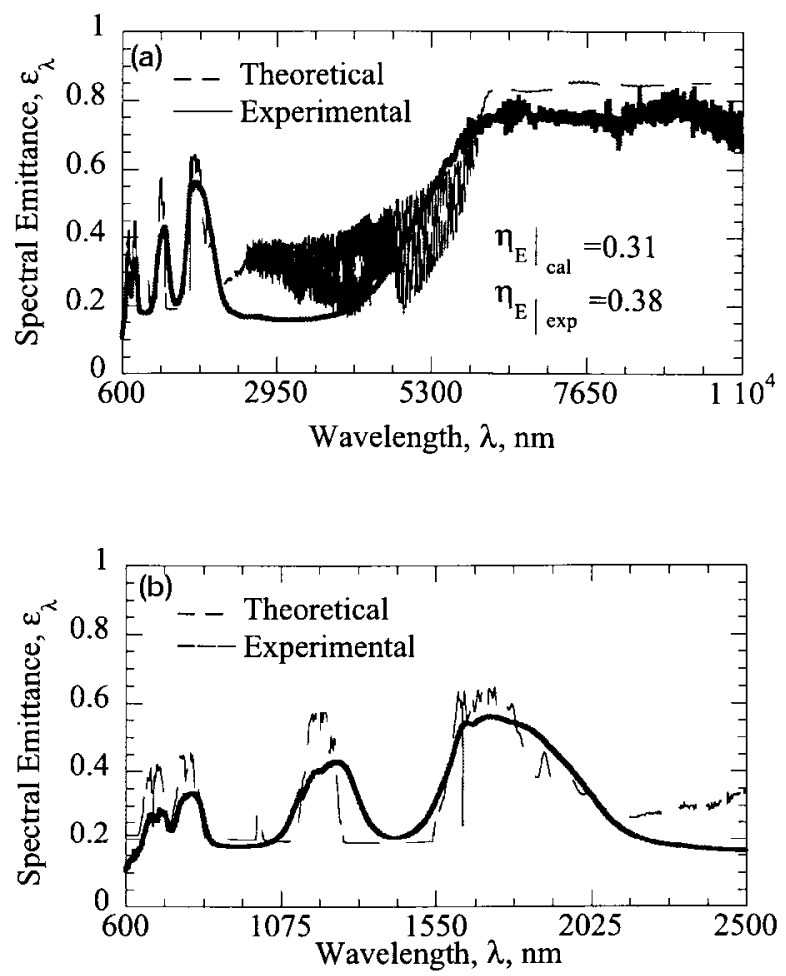

Fig. 8. Comparison of experimental and calculated spectral emittance of Thulium aluminum garnet $\left(\mathrm{Tm}_{3} \mathrm{Al}_{5} \mathrm{O}_{12}\right)$ with platinum substrate. Thickness, $\mathrm{d}=0.50 \mathrm{~mm}$, substrate temperature, $\mathrm{T}_{\mathrm{S}}=1700 \mathrm{~K}$, front face temperature, $\mathrm{T}_{\mathrm{f}}=1517 \mathrm{~K}, \Delta \mathrm{T}=0.0108$. (a) $600<\lambda<10,000 \mathrm{~nm}$. (b) $650<\lambda<2500 \mathrm{~nm}$. 

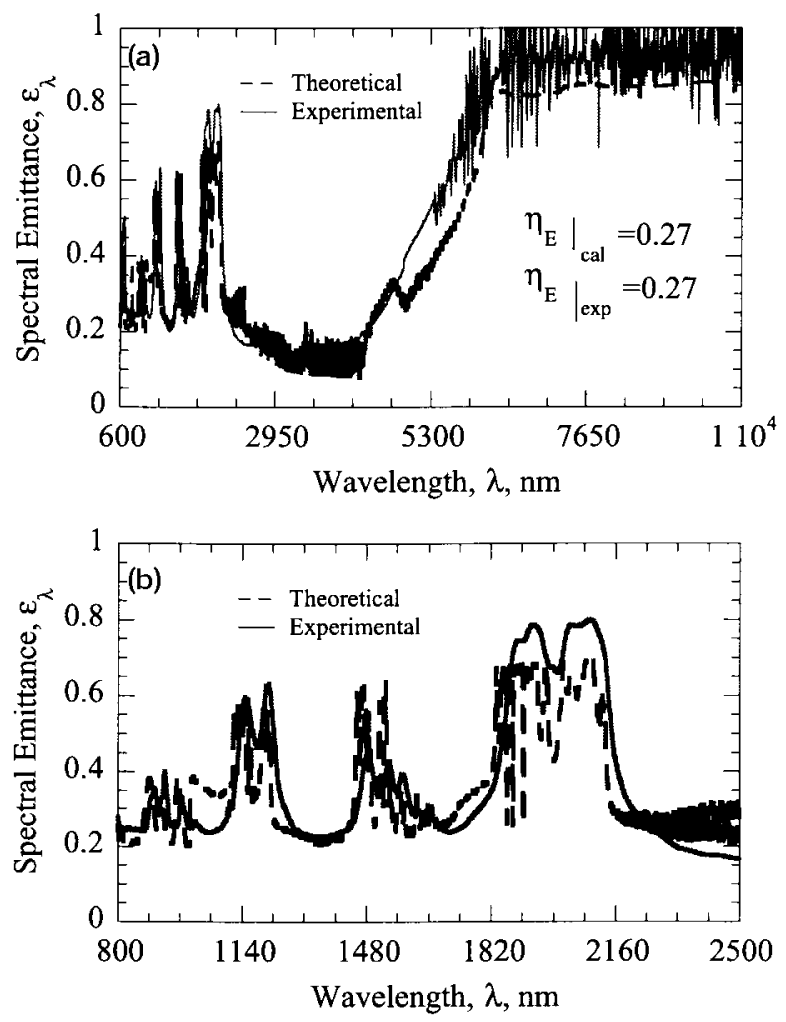

Fig. 9. Comparison of experimental and calculated spectral emittance of $\mathrm{Er}_{0.3} \mathrm{Ho}_{2.7} \mathrm{Al}_{5} \mathrm{O}_{12}$ with platinum substrate. Thickness, $\mathrm{d}=0.55 \mathrm{~mm}$, substrate temperature, $T_{\mathrm{S}}=1298 \mathrm{~K}$, front face temperature, $\mathrm{T}_{\mathrm{f}}=1194 \mathrm{~K}, \Delta \mathrm{T}=0.08$. (a) 600 $<\lambda<10,000 \mathrm{~nm}$. (b) $800<\lambda<2500 \mathrm{~nm}$. 

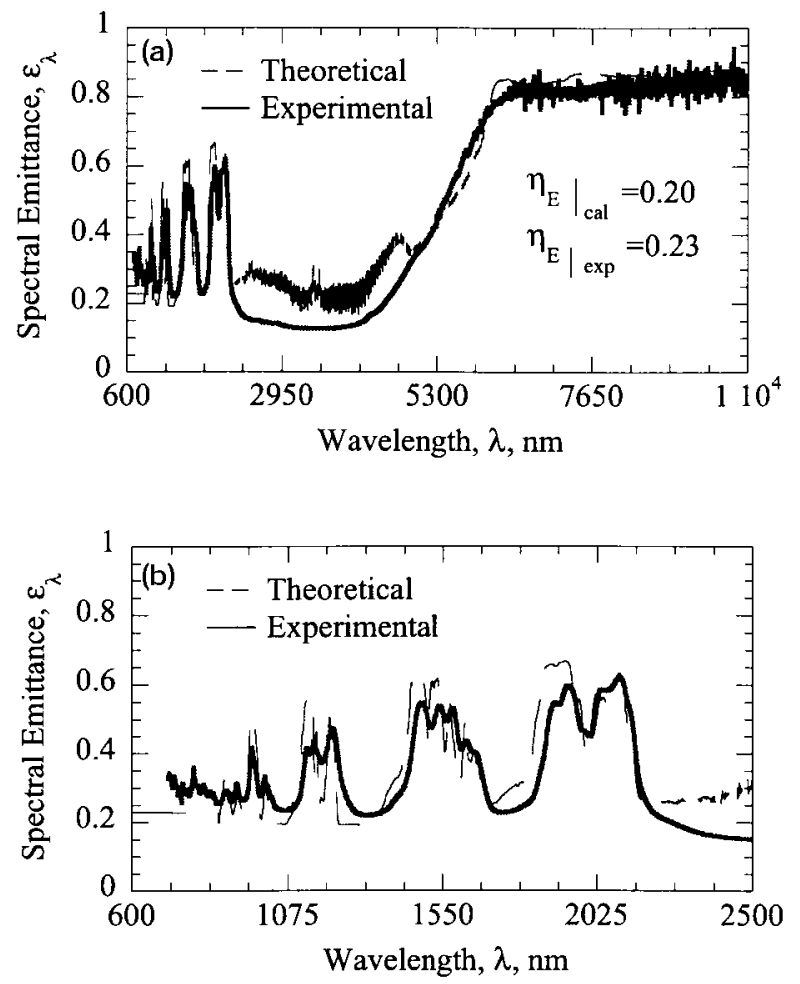

Fig. 10. Comparison of experimental and calculated spectral emittance of $\mathrm{Er}_{1.5} \mathrm{Ho}_{1.5} \mathrm{Al}_{5} \mathrm{O}_{12}$ with platinum substrate. Thickness, $\mathrm{d}=0.65 \mathrm{~mm}$, substrate temperature, $\mathrm{T}_{\mathrm{S}}=1218 \mathrm{~K}$, front face temperature, $\mathrm{T}_{\mathrm{f}}=1128 \mathrm{~K}, \Delta \mathrm{T}=0.074$. (a) 600 $<\boldsymbol{\lambda}<10,000 \mathrm{~nm}$. (b) $600<\boldsymbol{\lambda}<2500 \mathrm{~nm}$. 


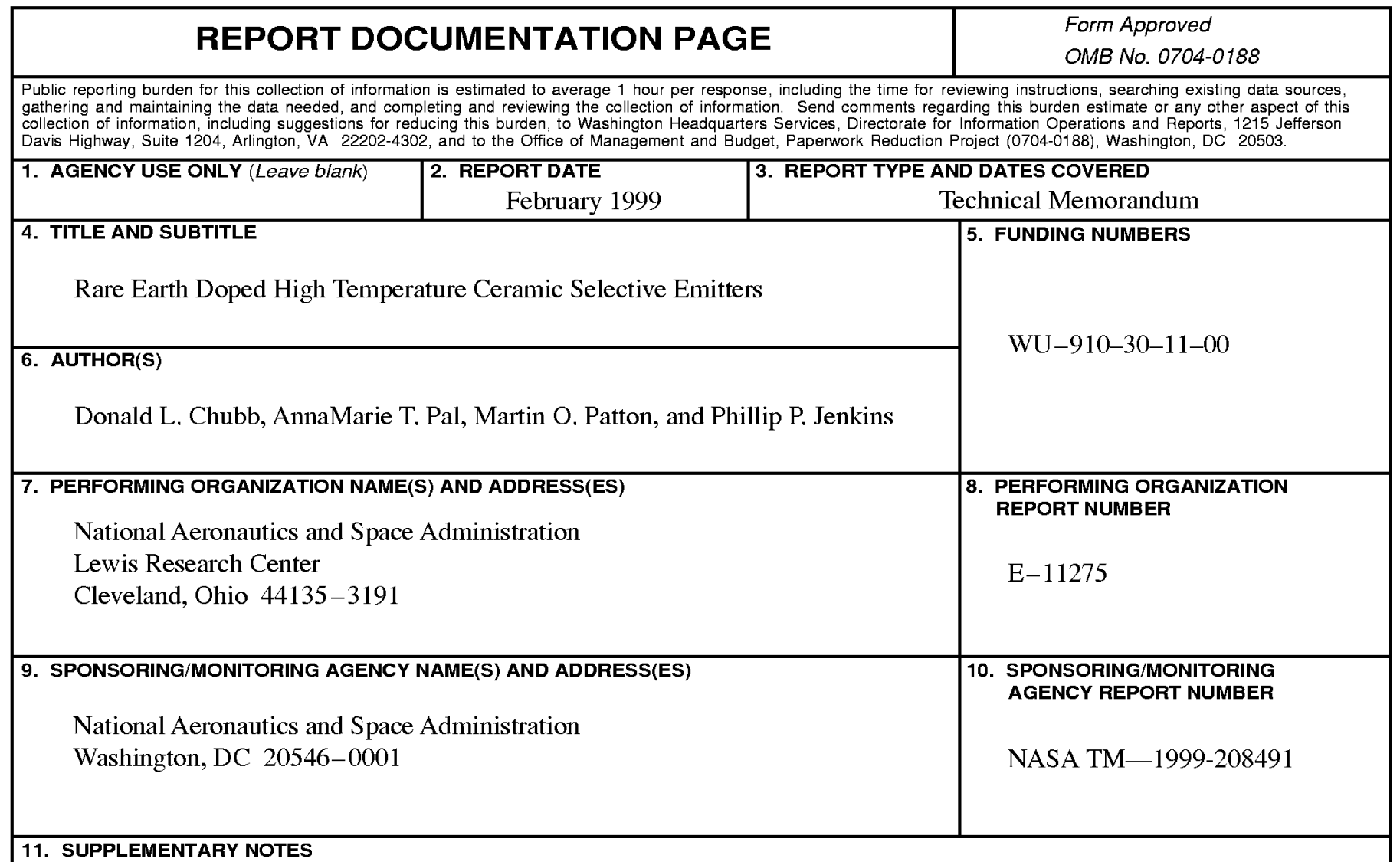

Donald L. Chubb, NASA Lewis Research Center; AnnaMarie T. Pal, Martin O. Patton, and Phillip P. Jenkins, Essential Research, Inc., 23811 Chagrin Blvd., Cleveland, Ohio 44122. Responsible person, Donald L. Chubb, organization code 5410, (216) 433-2242.

12a. DISTRIBUTION/AVAILABILITY STATEMENT 12b. DISTRIBUTION CODE

Unclassified - Unlimited

Subject Categories: 76 and $20 \quad$ Distribution: Nonstandard

This publication is available from the NASA Center for AeroSpace Information, (301) 621-0390.

13. ABSTRACT (Maximum 200 words)

As a result of their electron structure, rare earth ions in crystals at high temperature emit radiation in several narrow bands rather than in a continuous blackbody manner. This study develops a spectral emittance model for films of rare earth containing materials. Although there are several possible rare earth doped high temperature materials, this study was confined to rare earth aluminum garnets. Good agreement between experimental and theoretical spectral emittances was found for erbium, thulium and erbium-holmium aluminum garnets. Spectral emittances of these films are sensitive to temperature differences across the film. Emitter efficiency is also a sensitive function of temperature. For thulium aluminum garnet the efficiency is 0.38 at $1700 \mathrm{~K}$ but only 0.19 at $1262 \mathrm{~K}$.

\section{SUBJECT TERMS}

Selective emitter; Rare earths; Thermophotovoltaics

\begin{tabular}{|c|c|}
\hline $\begin{array}{c}\text { 17. SECURITY CLASSIFICATION } \\
\text { OF REPORT } \\
\text { Unclassified }\end{array}$ & $\begin{array}{c}\text { 18. SECURITY CLASSIFICATION } \\
\text { OF THIS PAGE } \\
\text { Unclassified }\end{array}$ \\
\hline
\end{tabular}

19. SECURITY CLASSIFICATION OF ABSTRACT

Unclassified
15. NUMBER OF PAGES

32

16. PRICE CODE

$\mathrm{A} 03$

20. LIMITATION OF ABSTRACT

Standard Form 298 (Rev. 2-89)

Prescribed by ANSI Std. Z39-18
$298-102$ 